\title{
Un romanceamiento bíblico neotestamentario desconocido y la primera versión castellana de la Catena aurea*
}

\author{
An unknow old Spanish translation of the New Testament \\ and the first version of the Catena aurea
}

\author{
Javier Rodríguez Molina \\ Universidad de Granada \\ jrmolina@ugr.es
}

\begin{abstract}
RESUMEN: Este artículo presenta el hallazgo de un texto medieval desconocido hasta el momento: fragmentos de un códice que contiene un romanceamiento bíblico neotestamentario de finales del siglo XIV distinto de todos los demás romanceamientos medievales identificados. La descripción del códice y la edición del texto se acompaña de un exhaustivo estudio linguíístico que permite fecharlo hacia 1400, así como de un análisis exegético que me ha posibilitado identificar parte del texto como una traducción de la Catena aurea de Tomás de Aquino al castellano, la primera identificada hasta el presente.
\end{abstract}

Palabras clave: códices bíblicos, Catena aurea, traducciones medievales, español medieval, traducciones de la biblia en español antiguo.

\footnotetext{
* Este trabajo se ha financiado con cargo al proyecto del MINECO "Procesos de cambio en la sintaxis del español peninsular" (FFI2012-31972). Agradezco a Andrés Enrique-Arias y Luis Girón Negrón el haber despertado en mí el interés por las biblias medievales, así como su generosa ayuda y disponibilidad para solventar mis muchas dudas sobre exégesis y materia bíblica. Gemma Avenoza merece un reconocimiento especial, no solo por la paciencia y detalle con la que leyó el manuscrito original, sino también por su asesoramiento codicológico y su generosidad para facilitarme signaturas y noticias de manuscritos. A María Jesús Torrens, Pedro Sánchez-Prieto Borja, Inés Fernández-Ordóñez, Juan Carlos Conde, Mónica Castillo, José Manuel Ruiz Asencio, José A. Pascual y Ramón Santiago Lacuesta debo preciosas observaciones sobre cuestiones lingüísticas y paleográficas que han ayudado en mucho a la mejora del trabajo. Agradezco también al AHN y a la archivera Elena Jiménez por haberme allanado el camino para la consulta e inspección del códice.
} 
ABSTRACT: This paper presents a previously unknown medieval text: fragments of a codex containing a late fourteenth century translation of the New Testament into Old Spanish. This translation does not match any known Old Spanish Bible translation. This article provides both a description of the codex and an edition of the text. Likewise it includes a comprehensive linguistic study which allows dating the manuscript circa 1400 and an exegetic analysis which makes it possibly to identify the glosses to the text as the earliest translation of Thomas Aquinas' Catena aurea into Spanish.

Keywords: Biblical codices, Catena aurea, Medieval Translations, Old Spanish, Old Spanish Bible translations.

Entre los varios fragmentos de códices que se agrupan en el libro 1.464 del Archivo Histórico Nacional (AHN) se encuentra un bifolio que contiene algunas secciones de una traducción romance de la Catena aurea de Tomás de Aquino, acompañado de un romanceamiento bíblico que traduce de la Vulgata dos segmentos del Nuevo Testamento (NT). De ninguno de estos dos textos se tenía noticia hasta el presente, de modo que el fragmento del AHN es importante por cuanto no solo contiene un nuevo romanceamiento bíblico distinto de todos los conocidos (Avenoza, 2008 y 2011), sino que transmite también la primera traducción romance identificada como tal de la Catena aurea de Tomás de Aquino.

El objetivo de este artículo es estudiar y sacar a la luz estos dos textos. A la transcripción y edición del bifolio preceden un análisis codicológico y paleográfico del fragmento en cuestión, una propuesta de datación basada en las particularidades linguísticas del texto, una identificación del contenido textual del códice y una exposición sumaria de los criterios de transcripción que he seguido. A falta de más datos, bautizaré el texto bíblico contenido en esta traducción de la Catena aurea como AHN, por no hacer mudanza en la costumbre de designar a las traducciones bíblicas por la sigla del códice que las contiene.

\section{ANÁLISIS CODICOLÓGICO Y PALEOGRÁFICO}

El bifolio que nos ocupa se cataloga como el fragmento 10 del libro 1464 del AHN (lleva un sello del AHN que reza ' $1464^{10}$ '), en el que se han reunido diversos restos de códices procedentes de monasterios burgaleses ${ }^{1}$. A tenor de

\footnotetext{
${ }^{1}$ La referencia completa es la siguiente: España. Ministerio de Educación, Cultura y Deporte. Archivo Histórico Nacional, Códices, L. 1464. Burgos. Hojas de códices. Bujedo. Herrera. Miraflores. Miranda de Ebro. Obarenes. Siglos XIII-XVI, no musicales, [21 fragmentos], fragmento $n^{\circ}$ 10. Las imágenes completas del bifolio (núm. 30-32) pueden consultarse en PARES (http:// pares.mcu.es). No me consta ninguna referencia previa a este fragmento en la bibliografía sobre
} 
una anotación manuscrita moderna en el margen superior de una de las hojas, este bifolio habría pertenecido a los fondos del monasterio de San Miguel del Monte de Miranda de $E_{b r o}{ }^{2}$. De acuerdo con la descripción que figura en el catálogo del AHN, el fragmento habría servido de cubierta a un legajo de documentos denominado "Burgos-Pap. Leg. 498"3.

Este fragmento 10 se corresponde con un bifolio infolio, confeccionado en pergamino; cada uno de los folios presenta en su estado actual de conservación unas dimensiones de 313 x $231 \mathrm{~mm}$. La letra del códice obedece al tipo gótica textual de finales del siglo XIV o tal vez principios del siglo $\mathrm{XV}^{4}$. El texto de la traducción de la Catena aurea está copiado a dos columnas cuya caja de escritura mide 264 x $230 \mathrm{~mm}$ aproximadamente, siendo el ancho de las columnas conservadas íntegras $110 \mathrm{~mm}$ y el intercolumnio de $15 \mathrm{~mm}$. La proporción de la caja de escritura es de 1,14 o, lo que es lo mismo, un valor intermedio entre el cuadrado y el área formada por dos rectángulos del número aureo situados uno sobre el otro (Ruiz, 2002: 186) ${ }^{5}$. No es una proporción demasiado común, pero su uso se puede justificar por la necesidad de subdividir las columnas para

biblias medievales (no figura en BETA, no lo menciona Avenoza, 2011), ni tampoco conozco noticia alguna referida a esta traducción de la Catena aurea, que no aparece en los repertorios de traducciones de Grespi (2004) y Alvar (2010).

${ }^{2}$ En la parte inferior del f. $2 \mathrm{r}$ hay una leyenda a lápiz en letra moderna que reza: "Burgos. Miranda de Ebro / Geronimos / S. Miguel del Monte". El monasterio de San Miguel del Monte o de la Morcuera se alzaba a $6 \mathrm{~km}$ de Miranda de Ebro. Se estableció como monasterio de la orden jerónima el 23 de noviembre de 1398, gracias a la donación por parte del obispo de Calahorra don Juan de Guzmán de una ermita que existía en el lugar; contó también con el patrocinio del obispo de Burgos don Juan de Villacreces (1394-1404), puesto que los territorios de Miranda alternaban entre ambas diócesis, así como del canciller Pedro López de Ayala. Entre 1419 y 1426 San Miguel funcionó como granja del vecino monasterio riojano de Santa María de la Estrella. El monasterio fue desamortizado en 1836, lo que provocó el saqueo de sus fondos y el comienzo de su decadencia (Revuelta, 1982: 241-44).

${ }^{3}$ La signatura antigua 498 corresponde hoy a Burgos, Clero, Rioseco, Benardos, Apeos s. XV-XVI-XVII, Leg. 1331, legajo en el que no he encontrado más restos del perdido códice del que formó parte el bifolio que nos ocupa.

${ }^{4}$ Gracias al informe que con gran generosidad me hizo llegar el paleógrafo José Manuel Ruiz Asencio, me inclino por llevar la escritura más bien a finales del XIV que a principios del XV, por las siguientes razones: (a): se observa todavía cierta tendencia a la angulosidad (parte superior de la $e$, la $o$, etc.), mientras que en el siglo XV esta se sustituye por redondeces; (b) no hay en el códice ningún elemento paleográfico típico del siglo XV, como la $a$ de lineta, la $g$ más cursiva, etc.; (c) la forma sencilla de la $\mathrm{R}$ mayúscula inicial apunta más al siglo XIV que al XV, época en que esta se vuelve más complicada; (d) la forma de la doble erre, compuesta de dos líneas verticales y encima una horizontal común, es la propia del siglo XIV; además, la $r$ de martillo tiende a bajar de la línea del renglón; (e) la forma de la $r$ final (una línea inclinada a la derecha y quebrada a la mitad), es muy típica del siglo XIV.

${ }^{5}$ Para reconstruir las dimensiones totales de la caja de escritura he calculado el espacio que ocuparían los caracteres perdidos y los he sumado a las dimensiones conservadas, por lo que el cálculo es aproximado. 
dar entrada al texto evangélico. Cada columna contiene entre 39-42 líneas de escritura y presenta rúbricas en rojo sobre los nombres de los doctores de la Iglesia. Algunas mayúsculas están decoradas también en rojo. El texto bíblico muestra asimismo una disposición columnar cuya caja de escritura es menor que la de la Catena, se encuentra todo él rubricado en rojo, contiene entre 8-32 líneas por columna y presenta un calderón de gran tamaño en el primer versículo de cada folio. La distribución a dos columnas se modifica cuando aparece el texto bíblico, dividiéndose en dos la columna en la que este se copia según la distribución siguiente: en la parte izquierda se copia el texto bíblico en tinta roja y en la parte derecha continúa el comentario.

Aunque el caracter fragmentario del testimonio impide conocer el destinatario del romanceamiento, se trata sin duda de un ejemplar cuidado, como muestran las numerosas rúbricas en rojo, el empleo del pergamino y el uso de tinta roja para escribir el texto bíblico, por lo que no sería descabellado pensar que la traducción estaba destinada a algún miembro de la nobleza ${ }^{6}$. No tiene notas de lectura de época contemporánea a la copia. Es preciso advertir que en una época indeterminada el bifolio fue guillotinado en sus extremos izquierdo y derecho, probablemente para ajustarlo a los documentos a los que servía de folio de guarda, por lo que una parte no pequeña del texto se ha perdido. Esta circunstancia impide saber si el códice presentaba reclamos o foliación. El último folio fue raspado a conciencia y borrado en su mayor parte, para escribir sobre él el siguiente asiento en letra del s. XVI:

[1r] No 16 CONDE DE SAL[INAS] Caxon 12: [cruz] lv $1^{\circ} \mid$ Conde de Salinas, Arca, Año de 1474:|Don Diego Gómez Sarmiento dio a este Monasterio|de San Miguel del Monte 60 maravedíes de renta en cada un | año perpetuamente porque le diessen la capilla principal | que entonces avía para entierro de Doña María de Mendoza. | El anno del 1538 se dio en Valladolid sentencia contra | el conde de Salinas condenándole a la paga anual | de dichos 60 maravedies, y al convento a que todos los días | diga un responso, el de la missa de alva, sobre la sepul|tura de la dicha Doña María. | Renta anual: 60 maravedies, | que son 176 Reales y 16 : maravedies. | Plazo: á 14 de Noviembre. | Consignacion en $\left.\right|^{7}$.

\footnotetext{
${ }^{6}$ Los códices bíblicos realizados en pergamino en el s. XV tienen, hasta donde sabemos, destinatarios nobles y, por lo general, se ejecutaron a instancias de un gran señor: así sucede con la Biblia de Arragel y con la Biblia del Marqués de Santillana (Morreale, 1958-59; Avenoza, 2009 y 2011: 199-205). Si tomamos como cierta la vinculación de AHN al monasterio de San Miguel del Monte, es probable que el promotor del romanceamiento perteneciera al linaje de los Ayala, pues se sabe que tanto el canciller Pedro López de Ayala como su hijo Fernán Pérez de Ayala fueron patronos del citado monasterio. Claro es que esta hipótesis es una mera conjetura que pasa por aceptar la hipótesis de que la Catena aurea del AHN se compuso en San Miguel del Monte, lo cual no estoy en condiciones de demostrar, ya que la única certeza es que el bifolio hoy custodiado en el AHN se encontraba efectivamente en dicho monasterio con posterioridad a 1538.

${ }^{7}$ Este Diego Gómez Sarmiento alude probablemente Diego Gómez Sarmiento y Villandandro, III conde de Salinas y conde de Ribadeo $(† 1562)$. Doña María de Mendoza debe corresponder a
} 
Este dato indica que al menos en el s. XVI el bifolio se encontraba en el monasterio de San Miguel del Monte, donde alguien lo raspó y reutilizó para escribir el documento arriba citado. Constituye un misterio si el bifolio del AHN vivía ya desencuadernado en esa fecha, y tampoco es posible determinar si el códice completo al que debió pertenecer el bifolio obraba en poder del monasterio de San Miguel del Monte con anterioridad a 1538, terminus a quo de escritura del asiento sobre el texto raspado, aunque el análisis lingüístico apunta a que el códice pudo elaborarse allí o en algún enclave cercano. La suerte que corrió el códice al que pertenecía el fragmento del AHN es, pues, un enigma que solo el hallazgo de más fragmentos del manuscrito o de la integridad del códice podrá dirimir ${ }^{8}$.

\section{DATACIÓN DEL CÓDICE: ASPECTOS LINGÜÍSTICOS}

No hay ningún dato en el bifolio conservado que permita aventurar su data tópica o cronológica, excepción hecha de la noticia escrita a lápiz en letra moderna que lo vincula al monasterio mirandés de San Miguel del Monte. El análisis linguiístico del texto conservado sustenta la hipótesis de que esta traducción romance de la Catena aurea pudo gestarse en el citado monasterio o en alguna región circunvecina situada hacia el este de Miranda de Ebro. La situación linguiística del texto posibilita también aventurar una fecha de redacción aproximada entre 1370 y 1450 que, con un margen más estrecho y arriesgado me atrevería a acotar incluso a $1380-1420^{9}$.

\footnotetext{
la esposa de Diego Pérez Sarmiento, primer conde de Salinas y respostero mayor de Juan II ( $† 1464)$, madre por consiguiente del segundo conde de Salinas, Diego Sarmiento $(\dagger 1474)$, hija de Juan Hurtado de Mendoza y, por tanto, bisabuela de este Diego Gómez Sarmiento, tercer conde de Salinas. Existió otro Diego Gómez Sarmiento de Villamayor en el s. XIV que fue señor de Salinas y murió en la batalla de Aljubarrota (1385), lo que dificulta su identificación con el personaje citado en el asiento del AHN, pues falleció 13 años antes de que se fundara el monasterio de San Miguel del Monte (para todo ello véase López de Haro, 1622: 530-534; Benito Ruano, 1957; Ansón Calvo, 1998: 13-17).

${ }^{8}$ No he hallado noticias directas de este códice en el Inventario de las escrituras y papeles que están en el archivo de la villa de Miranda de Ebro (BNE MSS/712, fols. 258r-261v, s. XVI y BNE MSS/834, fols. 123r-131v, s. XVII), ni en el Inventario de los Archivos, bibliotecas, obras de escultura, pintura, y enseres del Monasterio suprimido dela Estrella (AHN, Clero, Papeles, Legajo 3136, fols. 1r-2r, año de 1835), ni en el Inventario del archivo del monasterio jerónimo de Nuestra Señora de la Estrella (Logroño), ordenado ahcer [sic] por Fr. Francisco Javier Tramón (AHN, CODICES,L.1447, escrito en 1770) ni tampoco en el Protocolo y Memoria Lista Imbentario De todas las concordias, Priuilexios, Sentenzias Ademas escripturas [...] deste conbento [...] compuesto Nuebamente En este año de 1717 Por Nuestro Padre Fray Pedro Anttonio Vallexo, referido al monasterio de La Estrella (AHN, Clero, L. 5995). No obstante, en el Inventario de 1835, f. 1r figura la siguiente referencia: "La biblia regia en cinco tomos. / La obra de $S^{\text {to }}$. Tomas en catorce idem." y más adelante "Obra de $S^{\text {to. }}$. Tomas en diez tomos" (f. 1v).

${ }^{9}$ Nótese que analizo la lengua del fragmento como un todo, pese a que como sugiero luego el bifolio conserva en realidad dos textos, por lo que quien romanceó la Vulgata pudo no ser
} 


\subsection{Grafía y fonética}

El texto muestra tres características gráficas que apoyan datarlo antes de 1450: (a) conserva todas las efes iniciales procedentes de F- latina (fabló, forado, fuir, fezimos, fechas, faze, fijo); (b) mantiene intacto el sistema de sibilantes, a excepción de la oposición entre /s/ y /z/, ya que en posición intervocálica solo presenta la grafía $<\mathrm{s}>$ (soltasen, asi $)^{10}$; (c) conserva sin vocalizar la $<\mathrm{b}>$ en posición implosiva (debda, cabdal, çibdat); (d) no emplea las grafías <ss-, -ss->, ni <ff- $>$, apenas hace uso de <-ff-> (solo un ejemplo, effriamos), pero sí abunda en el uso de $<\mathrm{rr}->$ en posición inicial para representar /r/: 19 casos, por 15 de $<\mathrm{R}>$ y solo uno de $<\mathrm{r}->$; situación que, de acuerdo con el detallado estudio de Ueda (en prensa), casa mejor con el periodo 1375-1425 que con el sistema gráfico de mediados del siglo XIV. Asimismo, el códice no reduce el diptongo /ie/ en sieglo, castiello y en el formante mientre del adverbio, rasgo que apunta también a una antigüedad mayor que la segunda mitad del siglo $\mathrm{XV}^{11}$. Gracias a los documentos del CODEA y del CORDE se puede afinar bastante en la cronología de las formas castiello y sieglo. En el CODEA castiello no se documenta con posterioridad a 1435, mientras que el último ejemplo de sieglo es de $1369^{12}$. A pesar de todas las precauciones latentes en el empleo del CORDE, la frecuencia de las variantes castiello y sieglo en este corpus refleja

necesariamente la misma persona que tradujo la Catena aurea. La brevedad del fragmento conservado me impide, no obstante, afinar más el escalpelo lingüístico y deslindar los rasgos privativos de la lengua de cada uno de estos dos textos.

${ }^{10}$ En este rasgo el códice se conforma con los usos gráficos de la documentación medieval de Miranda de Ebro, que para 1393 muestran ya una indistinción completa de /s/ y /z/, sonidos representados siempre por <-s->, mientras que los documentos mirandeses anteriores a 1393 presentan confusiones de <-s-> y <-ss-> (Sánchez González de Herrero et al., 2014: 47-51).

${ }^{11} \mathrm{La}$ reducción del diptongo /ie/ en el diminutivo -iello > -illo y en palabras léxicas como rodiella, castiello o viéspera no se generaliza hasta el último tercio del s. XIV; las formas diptongadas perviven todavía con cierta frecuencia en los primeros decenios del s. XV, pero son raras después, ya que solo aparecen en el habla rústica de autores como Fray Íñigo de Mendoza, Torres Naharro o Rodrigo de Reinosa (Lapesa, 1981: 258-259, 273). El texto bíblico de La Biblia de Arragel (1422-30) ofrece todavía 6 ejemplos de castiello frente a 44 de castillo, pero ninguno ya de sieglo frente a 40 ejemplos de siglo. Los Evangelios de Martín de Lucena (a. 1458) no registran ya las variantes castiello y sieglo, pues solo emplean castillo (22 ejemplos) y siglo (42 ejemplos). Tomo estos datos de la búsqueda en Bibliamedieval (Enrique-Arias y Pueyo, 2008).

12 La cronología precisa de castiello $(s)$ a partir de 1300 es la siguiente (indico año del documento y lugar, para los documentos sin lugar conocido indico entre [ ] la región de procedencia de la carpeta del AHN que lo contiene): 1324 ([Navarra]), 1329 (Toledo), 1340 (Sevilla), 1341 (Rubielos de Mora), 1342 (Valladolid), 1346 (Toro), 1348 (Santander), 1363 (Sevilla), 1368 (Toledo), 1378 (Rubielos de Mora), 1380 (Medina del Campo), 1383 (Huesca), 1386 (Alcalá de Henares), 1409 (Calatayud), 1417 (Burgos), 1435 (Huesca). En cuanto a sieglo(s), su cronología en el CODEA desde 1300 ofrece los siguientes resultados: 1337 ([Navarra]), 1369 ([Navarra]) Búsquedas realizadas el 16/10/2015. 
un drástico descenso en torno a $1400^{13}$. A tenor de la distribución cronológica de estas variantes en el CODEA y en el CORDE, la situación lingüística del bifolio del AHN se corresponde con los textos anteriores a 1420.

Para tratar de fijar la fecha de redacción del texto podemos contrastar los usos gráficos de este códice con otros manuscritos fechados partiendo del análisis de dos rasgos concretos: (a) la presencia de $<\mathrm{h}->$ en las formas del verbo haber; (b) la escritura del adverbio así con ese sencilla. El códice del AHN emplea la grafía $<\mathrm{h}->$ en cuatro ocasiones con la tercera persona del verbo haber (ha mester, cosas que ha, han las riquezas, aquello que ha) y, sistemáticamente, escribe el adverbio así con una sola ese (13 casos, por ninguno de assî). La confrontación de estos dos usos gráficos con un conjunto de manuscritos fechados entre 1270 y 1480 sitúa la redacción del códice del AHN con posterioridad a 1350, ya que los códices originales del scriptorium alfonsí (Esc. Y-I-2, copiado h. 1270-74, BNE MSS/ 816, copiado h. 1270-80, Biblioteca Vaticana ms. Urb. Lat. 539, copiado en 1280) no conocen ejemplos de así con ese simple y son reacios a emplear la $h$ - en las formas del verbo haber. Por el contrario, los códices redactados o copiados entre 1300-1380, como Esc. K-III-4 (Libro de Apolonio), BNE MSS/9256 (Sumas de historia troyana), Esc. Y-III-9 (Poema de Alfonso XI) o Esc. Y-II-10 (Crónica de Alfonso XI), alternan ya así y assí (no todos, el Ordenamiento de Alcalá de 1348 según el ms. BNE RES/9 solo conoce assî), mientras que únicamente a finales del s. XIV se pueden encontrar manuscritos que ya solo presentan la variante con ese simple, como el ms. G del Libro de buen amor (ms. 19 RAE, copiado en 1389), junto a otros que todavía alternan ambas formas, como BNE MSS/10134 (Gran Crónica de España, copiado 1388-93). No es sino a partir de 1400 cuando se puede observar una neta preferencia de así sobre assí en códices como BNE MSS/9218 (Embajada a Tamorlán, copiado 1400-1450), el ms. S del Libro de buen amor (BuSal 2.663, copiado h. 1415), BNE MSS/7815 (Alonso de Cartagena, De officiis, copiado h. 1422-1500) o el códice de la Biblia de Arragel, conservado en el Palacio de Liria y copiado entre 1422-1430. Una cronología parecida aunque ligeramente más retrasada muestra el empleo de $<\mathrm{h}->$ con las formas del verbo haber, grafía que no presenta una difusión clara hasta mediados del s. XIV (Rodríguez Molina, 2009: nota 13) ${ }^{14}$.

${ }^{13}$ Búsqueda realizada el 2/10/2014. Solo se buscaron las formas correspondientes al singular. Los datos correspondientes al periodo 1350-99 arrojan 1.060 ejemplos de castiello y 28 de sieglo, para el periodo 1400-1419 el CORDE presenta 72 casos de castiello y 27 de sieglo; entre 1420 1449 solo hay 2 casos de castiello y 9 de sieglo, mientras que desde 1450 en adelante los ejemplos de castiello se reducen a solo 3 y desaparecen por completo los datos de sieglo. En la documentación de Miranda de Ebro se mantienen todavía algunos ejemplos de -ie- a finales del s. XV (Sánchez González de Herrero et al., 2014: 38).

${ }^{14}$ En la progresión de estos dos rasgos gráficos entran en juego diferentes factores que se correlacionan con condicionantes dialectales, tradiciones de escritura, preferencias personales, tipo 
La ausencia de apócope tanto en palabras léxicas como en los pronombres apoya también una datación en torno a 1400 (hay sin embargo un caso de apócope verbal, quier decir, y también aparece apócope en la forma sant, que alterna con santo), pues como señaló Lapesa (1981: 258) "en 1390 ó 1400 era ya absoluto el restablecimiento de la /-e/". En el caso de la dental final, el manuscrito tiende a generalizar la grafía sorda (verdat, segunt, caridat, omildat, salut, piadat, çibdat), rasgo que aconseja datar AHN antes de 1450 (Torrens, 2002: 188-200). Por último, hay que reseñar la forma posedía, con conservación de - $d$ - intervocálica, ya que se trata de un rasgo oriental, puesto que prácticamente solo los documentos aragoneses, riojanos y navarros emplean el verbo poseder, frente a la forma castellana poseer ${ }^{15}$.

\subsection{Morfología y sintaxis}

El texto conservado mantiene sistemáticamente la - $d$ - en las segundas personas de los verbos (entrardes, fallaredes, desatades, soltades) y presenta siempre la forma pronominal vos, sin reducir a $o s$, lo que apunta a una fecha de redacción anterior a $1450^{16}$. Por otra parte, la ausencia total de concordancia en los tiempos compuestos alinea el texto con el uso gramatical de las obras escritas a partir de $1350^{17}$.

de letra, etc., por lo que a falta de un estudio más detallado deben tomarse con precaución y considerarse como un indicio para datar el fragmento de AHN mejor después de 1350 que antes de esa fecha, pero no como instrumento de datación preciso.

${ }^{15}$ Hay ejemplos sueltos de poseder en documentos de Castilla y León, pero el grueso de los ejemplos se concentra en el oriente peninsular. En el CORDE los únicos ejemplos de poseder en textos literarios anteriores a 1400 son todos de Fernández de Heredia.

${ }^{16}$ La conservación de la - $d$ - podría reputarse como un signo de antigüedad del texto y aducirse como argumento para adelantar la fecha de redacción hacia 1370-1400, pero es preciso tener en cuenta que en la primera mitad del XV las formas con $-d$ - podían tener todavía prestigio y emplearse por escrito en textos solemnes, como es el caso de la Biblia. Como ha señalado EnriqueArias (2008), en la Biblia de Arragel (1422-1430) la pérdida de la - $d$ - es más frecuente en las glosas que en el texto bíblico, lo que revela una decisión consciente por adoptar las formas más conservadoras en la versión romance de la Biblia. Así las cosas, el valor probatorio del mantenimiento de $-d$ - en AHN como argumento de datación debe ponderarse en función del grado de conservadurismo lingüístico propio de la lengua de los romanceamientos bíblicos, máxime teniendo en cuenta que los cuatro ejemplos de formas verbales con - $d$ - de segunda persona figuran todos ellos en el texto bíblico (Lc 19: 28-36) y no en la traducción de la Catena. Por otra parte, los documentos medievales de Miranda de Ebro conservan de manera sistemática la $-d$ - de las segundas personas verbales incluso en la segunda mitad del siglo XV (Sánchez González de Herrero et al., 2014: 72). Así las cosas, este dato geográfico podría considerarse como suficiente justificación para la conservación de la $-d$ - en el texto. Como señala Eberenz (2000: 209-210), el cambio vos $>$ os no se consuma hasta la segunda mitad del s. XV, en paralelo con el retroceso de vos frente a vosotros; forma esta última que no registra el texto, como tampoco lo hace nosotros. No me atrevo a inferir una cronología de estos datos por la brevedad del fragmento conservado.

${ }^{17}$ Con todo, los ejemplos de falta de concordancia, que copan el $100 \%$ de los casos potenciales de concordancia (3/3) muestran todos ellos objetos léxicos o pronombres relativos (" $e$ las jus- 
Abundan en el texto los participios de presente, rasgo que apunta a una fecha de redacción posterior a 1350 o más bien a la primera mitad del siglo XV, verdadero punto de inflexión en el empleo del participio de presente ${ }^{18}$. En cuanto a los participios de pasado, localizo un ejemplo del participio débil del verbo romper (rrompido), forma que apenas se atestigua en CORDE con anterioridad a 1350 y que parece propia del oriente peninsular ${ }^{19}$.

El códice ofrece abundantes ejemplos de artículo con posesivo ${ }^{20}$, enclisis generalizada en la sintaxis pronominal, tres casos de interpolación (porque se non quesieron; si vos alguno preguntare; como les él dixo ${ }^{21}$, una forma de fu-

tificaçiones $e$ las dotrinas aya enbevido"; "como aya menospreçiado todas las cosas"; "las cosas que avían tomado"), categorías más proclives que los pronombres a la pérdida de la concordancia (Rodríguez Molina, 2010).

${ }^{18}$ En el texto el participio de presente se emplea como adjetivo (odre viejo non fue cabiente, pollino estante) y como sustantivo (los usantes, a todo aviente, los renunciantes, ascondientes, veyentes a sus parientes non fieles). La bibliografía sobre la diacronía de esta forma coincide en señalar su escaso uso con valor nominal antes del s. XV (Muñío Valverde, 1995). Se ha demostrado también la mayor incidencia de esta forma en los dialectos orientales (Pons, 2015: 404 410), de modo que la fuerte impronta del participio de presente en el texto (7 ejemplos en apenas dos folios) podría tomarse como un indicio de su adscripción dialectal al oriente peninsular, como así parecen indicar también otros fenómenos lingüísticos; sin perder de vista que el texto latino subyacente pudo condicionar también el empleo del participio de presente (aunque no siempre las traducciones de textos latinos traducen los participios latinos con formas en -nte, como justamente alerta Pons, 2015: 405). Con todo, debo señalar que el empleo de participios de presente parece ser también un rasgo típico de los romanceamientos bíblicos, que recurren a las formas en -nte para verter los participios de presente latinos de la Vulgata o el participio nominal semítico en las versiones deudoras de la biblia hebrea (Enrique-Arias, 2008). Calco del latín en el texto es sin duda el ejemplo de Lc 19: 32: stantem pullum] pollino estante.

19 Búsqueda realizada el 21/10/2014 para las variantes < rompido > y <rompido $>$ (no hay casos con $j$ en el CORDE). El ejemplo más antiguo del CORDE procede del Vidal Mayor, y luego aparece en documentos de Murcia, el Fuero general de Navarra, Fernández de Heredia y Villena.

${ }^{20}$ La frecuencia de la construcción artículo + posesivo + nombre frente a la construcción posesivo + nombre es del $56 \%$ en el texto, con cinco casos sobre un total de nueve ejemplos potenciales (la su ayuda, la su obra, las sus gracias, los mis enemigos, por dos veces este último). La frecuencia del artículo con posesivo experimenta un fuerte retroceso en la segunda mitad del s. XV (Lapesa, 1981: 281; Company, 2009: 778-779), por lo que tomando aisladamente este rasgo parece más sensato situar la redacción del texto antes de 1450, aunque como digo conviene no olvidar que la construcción de artículo + posesivo parece ser un rasgo escritural típico de los textos morales y bíblicos, en los que se emplea como recurso estilístico para dotar de solemnidad al texto (Eberenz, 2000; Enrique-Arias, 2008).

${ }^{21}$ En principio, la presencia de interpolación apunta más hacia la primera mitad del siglo XV que hacia la segunda, habida cuenta de que este fenómeno está ausente en muchas obras finiseculares (Eberenz, 2000: 166-168; Pons, 2015). Con todo, se ha señalado que la interpolación fue más frecuente en el norte que en el sur (Matute Martínez, 2004: 217 y 2013), por lo que si el texto fue redactado en Miranda de Ebro o en sus aledaños no debería extrañar la presencia del fenómeno, máxime teniendo en cuenta que la interpolación es un fenómeno presente en la documentación medieval mirandesa de finales del s. XIV (Sánchez González de Herrero et al., 2014: 66). 
turo sincopado (entrardes) ${ }^{22}$, imperfectos y pluscuamperfectos en -ía y soluciones diptongadas en los perfectos (traxieron, dixieron) ${ }^{23}$. La lengua del códice se atiene al sistema etimológico en el uso pronominal, ya que no registro casos de leísmo ni de laísmo ${ }^{24}$. Este dato, unido a los numerosos orientalismos del texto, invita a localizar la lengua del autor en una zona de la periferia de Castilla; y si bien Miranda de Ebro se ubica hoy muy cerca de la frontera entre el sistema etimológico y el referencial, pero dentro de este último (Fernández-Ordóñez, 1994: 116-118 y 2001: 454-456), los documentos medievales de Miranda se adscriben de forma general al sistema etimológico (Sánchez González de Herrero et al., 2014: 65). Por último, respecto de los pronombres hay que destacar las soluciones con metátesis en los imperativos con clítico adjunto (dezilde, mataldos), rasgo infrecuente antes del s. XIV, aunque se puede encontrar en documentos de Alfonso $\mathrm{X}^{25}$. La morfología de los adverbios en -mente presenta como forma única mientre, con diptongación y $-r$-. En principio, la presencia de estas formas en el texto, frecuentes en el s. XIII pero en claro retroceso desde el s. XIV, apunta a una fecha de redacción lo más temprana posible dentro del marco temporal acotado para el texto entre $1370-1450^{26}$.

${ }^{22}$ Aunque se trata del único caso de futuro sincopado del texto, es posible que tenga algún interés a la luz del trabajo de Moral del Hoyo (2015), donde se muestra la coincidencia del norte burgalés (Oña) e incluso de Santo Toribio de Liébana con Navarra en la preferencia absoluta por la variante sincopada en el siglo XIII. Sería, por tanto, una coincidencia más entre el norte castellano y el oriente peninsular.

${ }^{23}$ En el fragmento conservado solo figuran cuatro ejemplos, uno de imperfecto (oían) y tres de pluscuamperfectos (avían tomado, avía tomado, avía di[cho]).

${ }^{24}$ Los contextos donde potencialmente podría haber leísmo no son muchos (7 posibles casos), pero muestran situaciones contextuales diversas: (a) objeto humano masculino singular ( $e$ dixieron los que lo oían [a Jesucristo]); (b) objeto humano masculino plural (non quesieron turbarlos [a sus parientes]; e mataldos ante mí [los mis enemigos]; enbiándolos [a los judios] en el fuego); (c) objeto animado masculino singular (Desataldo $e$ traédmelo [el pollino]; $E$ si vos alguno preguntare por qué lo soltades [el pollino]; E mientra que ellos lo soltasen [el pollino]). Aunque ciertamente no se da una abundancia de contextos, el hecho de que en todos ellos aparezcan nombres humanos o animados, que son más proclives a verse afectados por el leísmo que los sustantivos inanimados (Fernández-Ordóñez 2001; Matute Martínez, 2004), invita a pensar que el autor del texto se atenía al sistema etimológico. Con todo, conviene ser cautos en este aspecto, ya que la brevedad del fragmento conservado no precluye la posible existencia de leísmo en el resto del códice, lamentablemente perdido. Los datos del fragmento pueden contrastarse con el panorama general que para el leísmo en el s. XV ofrece el estudio de Eberenz (2000: 209-245) y con el trabajo de Matute Martínez (2004).

${ }^{25}$ En CORDE pueden encontrarse ejemplos desde el s. XIII (de hecho, hay un dezilde en el códice del Poema de mio Cid, v. 389), pero habría que calibrar qué grado de fiabilidad se puede otorgar a estos ejemplos cuando los textos en los que aparece dezilde(s) en el XIII se han transmitido casi todos en copias tardías. La forma mataldo $(s)$ no aparece en CORDE hasta el s. XIV.

${ }^{26}$ Company (2014) subraya la escasa presencia de las formas diptongadas y con $-r$ en los textos de los s. XIV-XV, formas que no sobrepasan el $5 \%$ de las ocurrencias de los adverbios en -mente. Estas formas en -mientre son muy raras en los documentos del CODEA después de 1380 
En cuanto al sistema de subordinación, destaca el empleo de como + subjuntivo con valor causal; estructura típica del s. XV (Cano Aguilar, 1992: 333345) que en el texto aparece con casi todos los tiempos del subjuntivo: el presente ("como enpero ellos digan bueno a Jesucristo $e$ al dios del Testamento Viejo malo"), el pretérito imperfecto ("E fecho es como llegase a Bethania al monte que es llamado de las olivas embió dos disciplus suyos"), el futuro ("e como entrardes en él fallaredes un pollino de la asna atado") y el pretérito perfecto compuesto ("Ca como el omne ha consejero a Dios $e$ las justificaciones $e$ las dotrinas haya enbevido") ${ }^{27}$. El empleo de como + subjuntivo para verter el cum histórico latino en el versículo Lc 19: 29 agrupa el romanceamiento de AHN con el cuatrocentista de Martín de Lucena antes que con E6, ya que tanto AHN como Lucena, pero no la Biblia prealfonsí, emplean en este versículo como + subjuntivo ${ }^{28}$. Así, y teniendo en cuenta la escasez de ejemplos de como + pretérito imperfecto de subjuntivo antes del s. XV (Cano Aguilar, 1992), parece oportuno no datar el fragmento de $\mathrm{AHN}$ con anterioridad al último cuarto del s. XIV. Por otra parte, el empleo de como + pretérito perfecto compuesto en AHN es un rasgo lingüístico que aconseja fechar el texto en torno a 1385-1440, ya que los textos de los s. XIII y XIV desconocen esta estructura, que solo empiezo a documentar a partir de finales del s. $\mathrm{XIV}^{29}$. Por último, en el ámbito de

(Del Barrio, 2016), y en la documentación de Miranda de Ebro no llegan más allá de 1350 (Sánchez González de Herrero et al., 2014: 39). Es posible que la pervivencia de estas formas en los s. XIV-XV guarde relación con patrones de variación dialectal no conocidos hasta el momento, por lo que no habría que descartar que la forma mientre deba interpretarse más como rasgo dialectal que como marcador cronológico.

${ }^{27} \mathrm{El}$ empleo de como + presente de subjuntivo, relativamente frecuente en la lengua medieval, es particularmente acepto a los textos doctrinales; presente ya desde el s. XIV, constituye una estructura cuya frecuencia de empleo crece espectacularmente en el s. XV (Cano Aguilar, 1992: 336-339; Herrero, 2005: 337). Mucho menos frecuente es el empleo de como + imperfecto o pluscuamperfecto de subjuntivo, estructura muy rara antes de 1400 (véase Cano Aguilar, 1992 y Herrero, 2005: 338, nota 90 para una relación de los ejemplos más antiguos de esta estructura). Parece haber un amplio consenso en la bibliografía acerca del carácter imitativo de como + pretérito de subjuntivo, que constituye el reflejo romance del cum histórico latino (Cano Aguilar, 1992: 342; Herrero, 2005: 339).

${ }^{28}$ cum adpropinquasset] quando llego E6; commo llegase AHN; como llegase Lucena (Lc 19: 29). En Lc 19: 30 AHN emplea como + subjuntivo donde los demás testimonios bíblicos recurren a otra estructura: quod contra est in quod introeuntes invenietis] que esta delante uos. $e$ fallaredes E6; e como entrardes en él AHN; contra vos enel qual entrando fallaredes Lucena (Lc 19: 30). El ejemplo de entrardes de AHN en Lc 19:30 podría interpretarse también como futuro de indicativo sincopado.

${ }^{29}$ Esta cronología se sustenta en los datos acopiados para el estudio de la evolución de los tiempos compuestos en español antiguo que llevé a cabo en Rodríguez Molina (2010) sobre un amplio corpus de textos literarios de los s. XIII-XV. Pues bien, los textos de los s. XIII-XIV que despojé (Poema de mio Cid (h. 1200), Berceo, Vida de san Millán (1230) y Vida de santo Domingo (h. 1236), Alfonso X, General estoria (partes I, II y IV) (1270-1280), Alfonso X, Estoria de España (1270-74), Libro de buen amor (1322-1330), Sumas de historia troyana (h. 1350), 
las subordinadas relativas destaca la profusión del relativo compuesto el cual y la aparición de cual con antecedente adjunto, rasgo que apunta más al s. XV que al s. XIV (Lapesa, 2000: 390-392; Pons, 2007) ${ }^{30}$.

Finalmente, el manuscrito muestra una particularidad morfológica que creo me permite filiar dialectalmente el texto: me refiero al empleo del indefinido ningúo, forma atestiguada casi exclusivamente en la documentación de Navarra y el País Vasco ${ }^{31}$. Esta forma aparece por dos veces en el texto, frente a otros dos casos de ninguno, -na. En los dos últimos casos el manuscrito consigna claramente la lineta o escribe la segunda $n$, hecho que no se verifica en los dos primeros, como se puede constatar en las imágenes que reproduzco a continuación. De hecho, en una de estas imágenes se puede apreciar cómo la $g$ se escribe con lineta abreviativa de <ua>, degeneración de la antigua $a$ visigótica, que

Versión del roman de Troie de Alfonso XI (1340-50), Crónica de Alfonso XI (1344), Poema de Alfonso XI (1348), Crónica de Espanya de García de Eugui (h. 1390), Tercera partida de la Gran Crónica de España de Fernández de Heredia (h. 1385) emplean como quier que + pretérito perfecto de subjuntivo pero nunca como + pretérito perfecto de subjuntivo. Los primeros ejemplos de esta última estructura en el corpus que empleé en Rodríguez Molina (2010) los localizo en la Historia troyana de Fernández de Heredia (1385-1396) y, aunque no abundan en textos de la primera mitad del s. XV (están ausentes de la Embajada a Tamorlán [1406], la traducción de las Décadas de Tito Livio del canciller Ayala [1396-1400], de El Corbacho (1438) y de la Atalaya de las crónicas [1443-1454], ambos de Alfonso Martínez de Toledo, del Siervo libre de amor de Juan Rodríguez del Padrón [1435-1439], sí figuran con generosidad en la muy latinizante Historia troyana de Pedro de Chinchilla (1443).

${ }^{30}$ Ambos usos están ya presentes desde el s. XIII, pero no eran muy frecuentes; por otra parte, como señala Pons (2007), la estructura la cual ciudad se adscribe discursivamente en el s. XIII a los textos jurídicos y a la documentación notarial, mientras que su difusión a la lengua literaria no se verifica hasta mediados del s. XIV. De acuerdo con Pons (2007), el empleo de estas estructuras supuso un cambio desde arriba motivado por la influencia del latín y, en todas las épocas, se asoció esta estructura a la lengua de la distancia comunicativa. Solo en el breve fragmento de AHN registro 10 ejemplos del relativo compuesto el cual y dos de cual con atecedente adjunto ("La cual cosa non es a entender, Por la cual cosa sinifica la non piadat de los judíos").

${ }^{31}$ No son muchos los ejemplos de esta forma que pueden rastrearse en CORDE: encuentro esta forma en el Fuero general de Navarra (Versión C), traducido 1330 a quo (BNE MSS/248, s. XIV, fol. 22va "fidalgo ninguo", fol. 75vb "ninguo delos", fol. 75vb "ninguo que"), en la documentación medieval de Salvatierra ("en ningua cosa", año 1286, doc. n ${ }^{\circ}$, AMS Caja n ${ }^{\circ} 1$, Doc. $\mathrm{n}^{\circ}$ 4; "ningua cosa", año 1292, doc. no 13; Iñurreta Ambrosio, 1989) y Campezo ("non otro ninguo", año 1329, doc. nº 7; Pozuelo Rodríguez, 1998), en un manuscrito de la segunda parte de la General estoria (BNE MSS/10237, s. XIV, fol. 139rb, "ningua animalia"), en un impreso de las Siete Partidas (BNE INC/766, Sevilla, 1491, fol 9v, part. VII, tit. 6, ley 2 "a ninguuo"; posible errata por ninguno; pero en el CORDE figura ninguo) y hallo un caso de ningua en un documento de Alfonso X (Sánchez, 2000: 293, s. v. ninguno). No encuentro ejemplos en CODEA, ni tampoco figuran en la documentación medieval de Miranda de Ebro a tenor de su ausencia en el estudio lingüístico de Sánchez González de Herrero et al. (2014). Como se puede ver, en muchos de los casos la ausencia de tildes para la primera ene apoya la existencia de la forma ningúo. La concentración de esta forma en textos vasconavarros invita a suponerle un área de difusión geográfica muy acotada, así como a sospechar una procedencia similar para los tres ejemplos "alfonsíes", imposibles de filiar dialectalmente por falta de datos sobre los copistas de estos códices. 
en el texto corresponde a $u a$ (como en qual) y no a $n a^{32}$. Así las cosas, este ningúo del manuscrito refrenda la adscripción del texto a un área de influencia nororiental; quizá Álava o La Rioja.
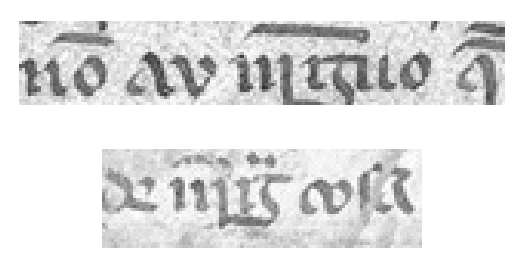

Ejemplos de ninguo, $-a$

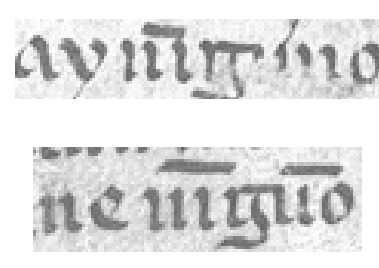

Ejemplos de ninguno, $-a$

\subsection{Léxico y morfología derivativa}

El examen de las palabras más particulares del texto permite aislar en él un conjunto de voces cuya cronología apunta a una fecha de redacción no anterior a 1350 y que, consideradas de forma unitaria, concuerdan con usos léxicos propios del oriente peninsular. En primer lugar, el códice presenta en cuatro ocasiones un extraño adjetivo en -ble, podible, del que no encuentro testimonios antes de mediados del s. XIV ${ }^{33}$. El texto documenta un gerundio preteando que se emplea para traducir el gerundio latino paciscendo, de PĂCISCOR (Mercator non tristatur in nundinis paciscendo quae possidet) y cuya interpretación más segura correspondería a una variante de pleitear, en el sentido de 'negociar' o 'ajustar, concertar' (DCECH, s. v. plazo); no resulta extraña la ausencia del diptongo (DCECH, s. $v$. plazo) si se considera una vía de entrada oriental para el verbo (cfr. catalán pret) y se tiene en cuenta su presencia en la documentación medieval de Miranda de Ebro (Sánchez González de Herrero et al., 2014: 119), tampoco plantea

\footnotetext{
${ }^{32}$ Podría pensarse también, claro, en que el copista ha olvidado la lineta o que la lineta de la primera $n$ vale para una segunda, aunque me inclino por dar carta de naturaleza a esta variante ningúo, $-a$, que como se muestra en la nota anterior aparece en otros textos. Refuerza esta idea el hecho de que los dos casos de ninguno, - $a$ aparecen en el romanceamiento bíblico, mientras que los dos de ningúo, - $a$ se encuentran en la traducción de la Catena aurea.

${ }^{33}$ Este adjetivo es muy poco frecuente, puesto que en el CORDE solo figuran nueve ejemplos: uno en la Traducción de la Vida de santa María Egipciaca (h. 1350), conservada en el MSS/780 de la BNE, fols. 25v-39r, así como en el ms. Esc. h-III-22, y los ocho restantes en el ms. S de Barlaam y Josafat (ms. 1.829 de la Biblioteca Universitaria de Estrasburgo, copiado en el s. XV); el hecho que no aparezcan en otros testimonios del Barlaam me hace sospechar que se deben al copista del XV. Puedo aportar tres ejemplos adicionales del Espéculo de los legos (14471455), según BNE MSS/94, base de la edición de Mohedano (1951: 7, 66 y 189). No lo registra el DCECH s. v. poder. Así las cosas, los escasos testimonios de este adjetivo podible se localizan todos en el marco cronológico 1350-1450.
} 
problemas el cambio $l>r$, típico del portugués (preito, espreitar) y de las variedades occidentales que, no obstante, llega incluso hasta Burgos (en la documentación de Oña hay varios casos de plior 'prior'). Pues bien, las formas sin diptongo del verbo pleitear apenas rebasan la segunda década del siglo XV, dato que proporciona un anclaje para fechar la lengua del fragmento ${ }^{34}$. Por último, la cronología de echamiento y punzamiento también apunta a una fecha de redacción del texto en torno a 1400: la primera, documentada desde el s. XIII, es rara después de 1450 , mientras que el DCECH s. v. punto estima que el verbo punzar, base de la forma punzamiento presente en el texto, se formó a su vez sobre punzón, sustantivo documentado desde el s. XIII (pace REW §6845), pero este diccionario no localiza hasta principios del s. XV las primeras documentaciones del verbo (no recoge el sustantivo punzamiento entre sus derivados), lo que invita a situar la gestación del sustantivo derivado punzamiento también al filo de $1400^{35}$.

Sin ninguna duda pasa por solución oriental el adjetivo somerano (cosas someranas) que presenta el texto para traducir un superna de la Catena latina, como oriental es la preposición somo con él relacionada ${ }^{36}$. Y oriental se me figura también el derivado tenederas, solución que se documenta casi exclusivamente en fuentes navarras y aragonesas (DCECH s. v. tener $)^{37}$. Si a estos datos

${ }^{34}$ Indica el DCECH s. v. plazo que pleito debió llegar a Castilla a través del aragonés. En CORDE aparecen 38 casos del verbo pletear (sin diptongo) y de sus derivados, 37 de ellos anteriores a 1415 (búsqueda realizada el 09/10/2014 sobre los segmentos <pletear*> y <pleteo*>). Tampoco parece que pletesía sobreviviese más allá de 1420, con la excepción de algunos ejemplos aislados. En los dialectos actuales de Navarra y La Rioja sí se registra la neutralización de /l/ : /r/, fenómeno del que se desconoce su profundidad histórica en estas áreas. Para la forma plior en el norte de Burgos, véase CORHEN.

35 Como testimonios fiables anteriores a 1500 de este sustantivo solo conozco los siguientes ejemplos cuatrocentistas: Pedro de Toledo, Guía de los perplejos de Maimónides (BNE MSS/10289, fol. 110v), Arte complida de cirugía (BNE MSS/2165, fols. 159r, 228r), Cirugía mayor de Lanfranco (BNE MSS/2147, fols. 227v, 159r) y Pronósticas de Gordonio (BNE INC/ 2438, fol. 36r).

${ }^{36}$ El carácter oriental de somo está fuera de toda duda (Octavio de Toledo, 2016: 46-47, nota 40). El adjetivo somerano, - $a$ conoció muy poco uso en la documentación medieval y, hasta donde se me alcanza, no lo registran los diccionarios: no figura en el DCECH s. v. somo, que sí cita su base somero, ni en el DHLE (1933-36), ni en el NTLLE. No por casualidad las dos primeras documentaciones de somerano, - $a$ en CORDE se encuentran en Fernández de Heredia y en Enrique de Villena; en el XV no se prodiga mucho en los textos salvo en las traducciones de textos médicos, que concentran más del $90 \%$ de los ejemplos. Interesante es el ejemplo de Villena, del Arte de trovar, por lo que de reflexión metalingüística contiene al calificar de antigua la voz somerano en 1423: "Lo que aora dezimos soberano en los libros antiguos está somerano, que parece que viene de summus. En el libro de Ramón Lull de Mallorca: «e si por aventura ellos sopiesen la manera cómo nós creemos en la somerana e divina Trinidad»" (Cátedra, 1994: 370, quien basa su edición en el ms. Esc. K-III-31). En cualquier caso, se trata de una voz cuyo arco cronológico en el CORDE se restringe a 1376-1500.

${ }^{37}$ Aunque aparece ya de manera aislada en el códice bíblico I-I-6 de h. 1250, todos los ejemplos posteriores son orientales: ejemplos de tenedero, - a pueden leerse en varios documentos del monasterio navarro de Irache de 1352 y 1395 (Lacarra y Martín Duque, 1986: 270, 368-369). 
unimos la presencia de la ya comentada variante dialectal ningúo, típica de Navarra y el País Vasco ( $\$ 2.2$ ), creo que queda bien perfilada la hipótesis de que el autor del texto era oriundo de Miranda de Ebro o de alguna comarca no muy distante hacia el oriente de esta población, pues su lengua presenta un castellano con caracteres comunes a los dialectos del oriente de Burgos, occidente de La Rioja o sur del País Vasco ${ }^{38}$.

\section{IDENTIFICACIÓN DEL TEXTO}

El fragmento del AHN conservado corresponde a una traducción al romance de dos secciones de la Catena aurea de Tomás de Aquino en la que se han insertado dos fragmentos del NT. El fragmento conservado corresponde a un bifolio que no es el central del cuaderno, por lo que no existe continuidad entre el texto del fol. 1 y el del fol. $2^{39}$. Describo, por lo tanto, cada fragmento de manera separada y lo mismo hago para los dos fragmentos del NT contenidos en la Catena aurea en romance.

a) Thomas de Aquino, Catena aurea, trad. del latín al castellano (¿13701420?). Traductor anónimo. Cap. XVIII (primer fragmento, fols. 1ra-vb); Cap. XIX (segundo fragmento, fols. 2ra-vb).

[Inc. texto primer fragmento f. 1ra] otras vertudes e porende dize e uen e sigueme que quiere dezjr en las otras cosas...

[Expl. texto primer fragmento f. 1vb] E semejable es la Razon delos | otros hermanos e desaparon por çierto el | padre e la madre e menospreçian el amor | de todo el parentesco por el amor de dios.

[Inc. texto segundo fragmento f. 2ra] quales asi como debdores desgastadores por di|nero las cosas que aujan tomado en aquellos dos | sieruos los quales ganaron son señalados los $\mid$ pocos los quales por dos uezes son enbiados $\mid$ a los labradores dela vjña...

[Expl. texto segundo fragmento f. 2vb] ala yglesia e estaua a liga[do a lo]s ligamjen[tos]

\footnotetext{
${ }^{38}$ No me atrevo a tildar como orientalismos otras voces del texto de las que sospecho dicha condición pero para las que carezco de pruebas concluyentes. Así sucede con forado, que en el CODEA figura una única vez en un documento de Teruel y en el CORDE parece mostar una preferencia por localizarse en textos orientales, o con los adjetivos semejable y convenible, que también muestran esta inclinación oriental, frente a las soluciones semejante y conveniente que acabarían triunfando en castellano.

${ }^{39} \mathrm{El}$ texto bíblico contenido el bifolio del AHN conserva hoy solo dos fragmentos pero por fuerza debía contener como mínimo toda la sección que va desde Lc 18: 24 a 19: 36, como atestiguan tanto la factura material del códice como la existencia de comentario exegético referido a versículos intermedios, algunos citados verbatim, por no mencionar que los códices latinos de la Catena contienen justamente toda esta sección Lc 18: 24 a 19: 36.
} 
b) Novum testamentum. Ev. secundum Lucam. Trad. del latín al castellano (¿1370-1420?). Traductor anónimo. Fragmento: 18: 24-30; 1ra-rb (en subcolumna); Fragmento: 19: 28-36, 2rb-va (en subcolumna).

[Rúbr. f. 1ra subcolumna] Testo

[Inc. texto f. 1ra subcolumna] $\mathrm{C}^{4}$ ihu [sic] xpo ue|yendo ael tris|te dixo que $\mathrm{g}$ |raue mientre entr|aran enel rreyno d | los çielos los que an | aueres. ca mas rra|fez cosa es pasar el | camello por el fora|do dela aguia...

[Expl. texto f. 1rb subcolumna] mucho mas eneste | tiempo e enel sieglo aue|nidero la uida per|durable.

[Rúbr. f. 2rb subcolumna] Testo

[Inc. texto f. 2rb subcolumna] $E^{4}$ sto dicho $\mid$ yua ihu $\mathrm{x}^{\mathrm{o}}$. | ante ellos $\mid$ e subio a iherusalem e fe|cho es como llega|se a bethania al m|onte que es llamado | delas oliuas...

[Expl. texto f. 2va subcolumna] enel camino.

\subsection{El texto bíblico}

El bifolio del AHN contiene dos fragmentos en romance del NT correspondientes al evangelio de san Lucas (Lc 18: 24-30 y 19: 28-36). Este romanceamiento no coincide ni con la Biblia prealfonsí ni con los Evangelios en romance de Martín de Lucena, únicos romanceamientos de los Evangelios basados en la Vulgata conocidos hasta la fecha; tal y como se desprende del cotejo de Lucas $18: 25$ y $19: 30^{40}$ :

\begin{tabular}{|c|c|c|c|}
\hline E6/E8 & Lucena & AHN & Vulgata \\
\hline $\begin{array}{l}\text { Ca mas ligera cosa } \\
\text { es el camello passar } \\
\text { por el forado del }\end{array}$ & $\begin{array}{l}\text { masera cosa es camello pasar por } \\
\text { el ojo del aguja que }\end{array}$ & $\begin{array}{l}\text { ca más rafez cosa es } \\
\text { pasar el camello por } \\
\text { el forado de la agu- }\end{array}$ & $\begin{array}{l}\text { facilius est enim ca- } \\
\text { melum per foramen } \\
\text { acus transire quam }\end{array}$ \\
\hline
\end{tabular}

${ }^{40}$ El códice E6 (= Esc. I-I-6, copiado h. 1250), en conjunción con el códice E8 (Esc. I-I-8, copiado h. 1400), contiene un romanceamiento bíblico casi completo a partir de la Vulgata que es anterior a las grandes obras alfonsíes (Enrique-Arias, 2010; Avenoza, 2011: 21-52). Cito E6 por la transcripción paleográfica de Enrique-Arias (2010), a la que he eliminado la indicación de separación de líneas. Los Evangelios en romance se han transmitido en el MSS/9556 de la Biblioteca Nacional de Madrid, un códice en pergamino propiedad del cardenal Pedro González de Mendoza (1428-1495), hijo de Íñigo López de Mendoza. Este romanceamiento, realizado por Martín de Lucena "El Macabeo", formaría serie con la biblia romanceada contenida en el MSS/ 10288 de la Biblioteca Nacional de Madrid, copiado a. 1458 (Avenoza, 2008: 51-53 y 2011: 149) y con el Pentateuco de E4 (Pueyo y Enrique-Arias, 2013). De acuerdo con Pueyo y EnriqueArias (2013) el Marqués de Santillana fue el promotor de este romanceamiento, al que bautizan como Biblia del Marqués de Santillana. Cito a Lucena por el manuscrito de la BNE. Tomo el texto de la Vulgata de la edición de Weber y Gryson (2007). 


\begin{tabular}{|c|c|c|c|}
\hline $\begin{array}{l}\text { aguia. que entrar el } \\
\text { rico en el regno de } \\
\text { los cielos. }\end{array}$ & $\begin{array}{l}\text { el Rico entrar enel } \\
\text { Regno de dios }\end{array}$ & $\begin{array}{l}\text { ja que el rico entrar } \\
\text { en } e l \text { regno de Dios }\end{array}$ & $\begin{array}{l}\text { divitem intrare in } \\
\text { regnum Dei }\end{array}$ \\
\hline $\begin{array}{l}\text { e dixo les. Jd a } \\
\text { aquel castiello que } \\
\text { esta delante uos. e } \\
\text { fallaredes u npollino } \\
\text { de asna atado. en } \\
\text { que nunqua caualgo } \\
\text { ombre. Desatat le e } \\
\text { duzit me lo. }\end{array}$ & $\begin{array}{l}\text { disjente yd enel cas- } \\
\text { tillo que es contra } \\
\text { vos enel qual en- } \\
\text { trando fallaredes vn } \\
\text { plljno de asna atado } \\
\text { enel qual nunca al- } \\
\text { guno se asento de- } \\
\text { sataldo \& traeldo }\end{array}$ & $\begin{array}{l}e \text { díxoles: "Id }<\text { a> } \\
\text { aquel castiello que } \\
\text { es contra vós e co- } \\
\text { mo entrardes en él } \\
\text { fallaredes un pollino } \\
\text { de la asna atado, } \\
\text { sobre el cual aún } \\
\text { nunca estudo onme } \\
\text { ninguno. Desataldo } \\
\text { e traédmelo". }\end{array}$ & $\begin{array}{l}\text { Dicens ite in caste- } \\
\text { llum quod contra est } \\
\text { in quod introeuntes } \\
\text { invenietis pullum } \\
\text { asinae alligatum cui } \\
\text { nemo umquam ho- } \\
\text { minum sedit solvite } \\
\text { illum et adducite }\end{array}$ \\
\hline
\end{tabular}

\subsection{La traducción de la Catena aurea}

El texto principal del bifolio del AHN corresponde a una traducción al romance de la Catena aurea de santo Tomás de Aquino, lo que fija el año 1268 como terminus a quo para la composición del texto ${ }^{41}$. El cotejo de algunas secciones del códice del AHN con el texto latino de la Catena aurea (sigo la edición de Guarienti, 1953: 249-250, 258) bastará para sustentar mi aserto:

\begin{tabular}{|l|l|}
\hline \multicolumn{1}{|c|}{ CATENA AUREA } & \multicolumn{1}{|c|}{ AHN } \\
\hline CYRILluS. Princeps autem ille vini re- & CERILLO Ca qu'ell príncipe [borrón]ndo \\
centis capax non fuit, vetus uter existens; & odre viejo, non fue cabiente para rescibir \\
sed tristia ruptus est; unde sequitur His & vino nuevo, mas es ronpido por tristeza; \\
ille auditis, contristatus est, quia dives & onde síguese "Entristecido es él por estas \\
erat valde. BASILIUS. Mercator non tris- & cosas oídas, porque era muy rico". SANT \\
tatur in nundinis paciscendo quae possi- & BASILIO El mercador non se entristece en \\
det, acquirendo sibi opportuna; tu vero & las ferias preteando las cosas que ha ga- \\
tristaris pulverem dans, ut acquiras vitam & nado, las cosas que ha son convenibles a \\
beatam. & $\begin{array}{l}\text { él; e tú eres entristecido e das polvo por } \\
\text { que ganes la vida bien aventurada. }\end{array}$ \\
\hline
\end{tabular}

${ }^{41}$ Se conoce como Catena aurea al comentario de los cuatro evangelios que Tomás de Aquino realizó a petición de Urbano IV entre 1262-1268. El propósito de la Catena aurea fue el mismo que movió a los compiladores de la Glossa ordinaria de Laon en el s. XII, esto es, glosar y sintetizar el mayor número de comentarios de los padres de la Iglesia, con la diferencia de que el texto de Aquino presenta la compilación de citas patrísticas versículo tras versículo en una expositio continua que permite una lectura ininterrumpida (Torrell, 2002: 154-155). Mérito es de santo Tomás el haber reunido un material de excepcional calidad y cantidad, pues cita a 57 autores griegos y a 22 latinos, algunos de los cuales, como Teofilacto, no se conocían en occidente (Torrell, 2002: 157). Esta obra gozó de una difusión extraordinaria, ya que de ella se han conservado cientos de manuscritos medievales. 
THEOPHYLACTUS. Apud homines ergo, quorum serpit intentio ad terrena, impossibilis est salus, ut dictum est; apud Deum vero possibilis est.

AUGUSTINUS (ut supra). Per quod designat impietatem Iudaeorum, quia ad eum noluerunt converti. THEOPHYLACTUS. Quos tradidit morti, mittens eos in ignem exteriorem; sed et in hoc mundo mactati sunt flebiliter ab exercitu Romanorum. Chrysostomus. Haec contra Marcionistas competunt.
TEÓFILO Pues así es ante los omnes, la entención de los cuales se rastra a las cosas terrenales, non es podible la salut segunt dicho es, e cuanto a Dios, es podible.

SANTO AGOSTÍN DE LAS CUESTIONES DEL EVANGELIO. Por la cual cosa sinifica la non piadat de los judíos, porque se non quesieron convertir a él. TEÓFILO. Los cuales dio a la muerte enbiándolos en $e$ l fuego de fuera, mas aún en este mundo son muerto[s] llorosa mientre de la conpaña de los romanos. SANT GRISÓSTOMO. Estas cosas conviene contra unos here|ges llamados marcionistas

El texto de AHN no se aparta del texto latino de la Catena excepción hecha de algunos yerros ocasionales de traducción, que se indican en el texto con la correspondiente nota a pie de página, así como de un error en uno de los epígrafes, en el que AHN presenta de modo incomprensible Theófilo allí donde el doctor angélico refiere a Cirilo (Guarienti, 1953: 249) ${ }^{42}$. Los doctores allegados en el presente texto son los siguientes: Teofilacto (theofilo), san Juan Grisóstomo (grisostomo), Beda el Venerable (beda), san Basilio (sant Basilio), san Cirilo de Alejandría (çerillo), Tito (tito) y san Agustín (sant agostín) ${ }^{43}$. Como acabo de mostrar, el orden de los padres que sigue AHN es idéntico al del texto latino de la Catena, lo que constituye otro argumento más para identificar la fuente de la traducción.

${ }^{42}$ Es posible que este yerro se deba a un simple error mecánico de copia del manuscrito latino de la Catena que sirvió de texto subyacente, que podría por tanto traer de suyo Theofylactus y no Cyrillus; tampoco puede desecharse la idea de que el copista encontrara dificultad en la resolución de la abreviatura del nombre del comentarista o que se equivocara por salto de igual a igual.

${ }^{43}$ Enigmática resulta la forma çerillo como variante de Cirilo del manuscrito, que debe corresponder por fuerza a un comentarista y que, basándome en la Catena aurea, no puede sino corresponder a Cirilo de Alejandría. Es muy posible que en el códice latino que sirvió como texto bíblico subyacente al romanceamiento de AHN los nombres de los comentaristas aparecieran abreviados (así sucede en la Catena aurea latina del ms. ACA, Manuscritos, Ripoll, 36, f. 2r, que abrevia Teofilacto como thopli y Crisóstomo como criso), lo que explicaría la forma çerillo y el hecho de que Teofilacto aparezca como Theófilo, si bien la Traducción compendiosa de los comentarios al evangelio de san Juan de santo Tomás de Aquino conservada en el ms. 108 de la Biblioteca de Castilla-La Mancha (que juzgo posible traducción de la Catena aurea) presenta también esta forma (escrita como teofilo y teophilo). Así las cosas, no se debe descartar que el cambio de Teofilacto por Teófilo corresponda a una simple trivialización del poco conocido Teofilacto por Teófilo, nombre mucho más común y familiar para el traductor castellano al tratarse del destinatario del evangelio de san Lucas. 
El cotejo del fragmento del AHN con los textos neotestamentarios acompañados de comentario que se conocen permite asegurar que aquel no guarda relación con ninguno de estos. Así, el comentario exegético de AHN ofrece un texto diferente de los Evangelios moralizados de López de Salamanca (Zamora: Antón de Centenera, 22 mayo, 1490), pues estos presentan solo el comentario en vernáculo, pero el texto bíblico se encuentra en latín ${ }^{44}$; tampoco coincide con las Epístolas y evangelios de Gonzalo de Santa María (Zaragoza: Pablo de Hurus, 1485; Salamanca s.e. 1493) ${ }^{45}$, ni con la Suma de Nicolás de Lira (BNE MSS/1028210287, que por otra parte solo alcanza los libros del Antiguo Testamento); ninguna relación existe entre AHN y la Biblia de Osuna (BNE MSS/10232; Avenoza, 2008: 58) y, por último, AHN tampoco lee de consuno con la Traducción compendiosa de los comentarios al Evangelio de Tomás de Aquino (Avenoza, 2008) ${ }^{46}$.

Pese a no coincidir con este último texto, debo destacar la conveniencia de estudiar la posible conexión de los dos códices toledanos que conservan esta Traducción compendiosa con el testimonio del AHN, ya que los tres manuscritos contienen, en mi opinión, una traducción romance de la Catena aurea de Santo Tomás; traducción empero no coincidente puesto que en AHN solo se ha conservado el comentario a Lucas, mientras que el ms. 83 de Toledo transmite únicamente el comentario a Mateo y el ms. 108 el de Juan: solo un estudio detenido de estos tres testimonios podrá certificar si existe o no alguna relación entre ellos ${ }^{47}$, pero si estoy en lo cierto, el fragmento del AHN y estos dos ma-

${ }^{44}$ He cotejado el texto de López de Salamanca a partir de ejemplar BNE INC/635. De esta obra se conserva una segunda parte en la Biblioteca capitular de Salamanca, caj. 66, leg. 1, $\mathrm{n}^{\circ} 2$, manuscrito copiado entre 1450-1470 (Avenoza, 2010: 461). Juan López de Salamanca (h. 1385¿1479?) fue confesor de Leonor Pimentel, duquesa de Plasencia. Su obra adquiere tintes de sermón erudito, ya que se trata de una traducción instrumental y no de una biblia per se.

${ }^{45}$ El comentario de García de Santa María se basa en la Postilla super Epistolas et Evangelia (1437) del dominico Guillermo de París (Morreale, 1958-59; Avenoza, 2008: 55-56) y no en la Catena aurea. Para el cotejo del texto me he servido de la edición de Collijn y Staaf (1908: 232-233).

46 Esta traducción compendiosa es el título que Esteve (1942: 77, 93) adjudicó al contenido de dos manuscritos en papel del fondo Borbón-Lorenzana de la antigua biblioteca pública de Toledo, actual Biblioteca de Castilla-La Mancha. El ms. 83 contiene los comentarios al evangelio de san Mateo y el ms. 108 contiene los comentarios al evangelio de san Juan. Ambos manuscritos parecen ser una traducción de la Catena aurea de Tomás de Aquino, hipótesis que solo un examen minucioso de su contenido permitirá aquilatar. Avenoza data ambos códices como de mediados del s. XIV, retrasando ligeramente la datación de Esteve (1942: 77, 93), que los situó a finales de dicha centuria. Desde la descripción de Esteve (1942) se han agrupado estos dos códices como pertenecientes a un mismo texto (y así figuran en Avenoza, 2008: 67), pero habría que comprobar que efectivamente es así. Para la descripción de ambos manuscritos, que no parecen compartir un proyecto codicológico común, véase Esteve (1942: 77, 93) y Avenoza (2008: 67).

${ }^{47}$ Existe una clara diferencia de factura entre AHN y estos códices: aquel es un ejemplar en pergamino y de cierto lujo, mientras que los códices de Toledo, copiados sobre papel, con ser copias esmeradas son manuscritos utilitarios que han sido manejados, corregidos y anotados (Avenoza, 2008: 67). 
nuscritos toledanos constituyen hasta el momento las únicas tres copias conocidas de la traducción castellana de la Catena aurea de Tomás de Aquino ${ }^{48}$.

Gracias al texto de la Catena romance es posible entresacar algunas citas de versículos bíblicos distintos al pasaje contenido en el bifolio del AHN (Lc 18: 24-30 y 19: 28-36); versículos cuya traducción tampoco coincide ni con el texto de E6 ni con el de Martín de Lucena, tal y como se muestra a continuación:

\begin{tabular}{|c|c|c|c|c|}
\hline versículo & E6/E8 & Lucena & AHN (Catena) & Vulgata \\
\hline Lc 18: 22 & e sigue me & $\&$ ven $\&$ sigueme & $E$ ven $e$ sígueme & $\begin{array}{l}\text { et veni sequere } \\
\text { me }\end{array}$ \\
\hline Lc 18: 23 & $\begin{array}{l}\text { Quand esto oyo } \\
\text { el otro; fue triste } \\
\text { ca era muy rico }\end{array}$ & $\begin{array}{l}\text { E el oyendo estas } \\
\text { cosas entristeçio- } \\
\text { se ca era muy Ri- } \\
\text { co }\end{array}$ & $\begin{array}{l}\text { Entristecido es } \\
\text { él por estas co- } \\
\text { sas oídas, porque } \\
\text { era muy rico }\end{array}$ & $\begin{array}{l}\text { His ille auditis con- } \\
\text { tristatus est quia } \\
\text { dives erat valde }\end{array}$ \\
\hline Mt 19: 27 & $\begin{array}{l}\text { pues que gualar- } \\
\text { don auremos? }\end{array}$ & pues que será anos & $\begin{array}{l}\text { Pues así es, ¿qué } \\
\text { será a nós? }\end{array}$ & $\begin{array}{l}\text { quid ergo erit no- } \\
\text { bis }\end{array}$ \\
\hline Mat 19: 27 & e seguiemos ati & $\&$ segujmos te & E seguímoste & et secuti sumus te \\
\hline Lc 19: 25 & Falta en E6 & $\begin{array}{l}\& \text { dixeRon le se- } \\
\text { nor tiene diez njnas }\end{array}$ & $\begin{array}{l}E \text { dixiéronle: "Se- } \\
\text { ñor, diez dineros } \\
\text { ha" }\end{array}$ & $\begin{array}{l}\text { et dixerunt ei do- } \\
\text { mine habet decem } \\
\text { mnas }\end{array}$ \\
\hline Lc 19: 26 & $\begin{array}{l}\text { Mas yo uos di- } \\
\text { go; que daran a } \\
\text { tod ombre que } \\
\text { ouie|re e sera }\end{array}$ & $\mid \begin{array}{l}\text { digo vos que } \\
\text { atodo aviente se } \\
\text { dara \& de aquel } \\
\text { que non tiene lo }\end{array}$ & $\begin{array}{l}\text { Dígovos por } \\
\text { cierto que será } \\
\text { dado a todo } \\
\text { aviente. }\end{array}$ & $\begin{array}{l}\text { Dico autem vo- } \\
\text { bis quia omni ha- } \\
\text { benti dabitur ab } \\
\text { eo autem qui non }\end{array}$ \\
\hline
\end{tabular}

${ }^{48}$ Este texto no figura como tal en los repertorios por mí conocidos de traducciones cuatrocentistas, caso de Alvar (2010) y Grespi (2004: 276-278), cuyo exhaustivo catálogo de traducciones de obras latinas de la BNE y El Escorial solo registra como traducciones de santo Tomás la Declaración del credo, De regimine principum y de la Summa contra gentiles. Me informa Gemma Avenoza de que en portugués, pero no en catalán, existen también restos fragmentarios de la Catena: BETA texid 6316 Thomas de Aquino, Carta Dedicatória a Urbano IV, traduzido/a 1476?1525?; BETA texid 14903 Thomas de Aquino, Comentário sobre o Evangelho de São João, traduzido/a 1500 ad quem; BETA texid 6314 Thomas de Aquino, Comentário sobre o Evangelho de São Mateo (tr. desconhecido), traduzido/a1476?-1525?; BETA texid 6315 Thomas de Aquino, Proêmio do Santo Evangelho Sagrado (tr. desconhecido), traduzido/a 1476? - 1525?; por un lado, habría que comprobar si todos estos textos no son sino traducciones fragmentarias de la Catena aurea y, por lo tanto, deberían unificarse como copias diferentes del mismo texto; por otro lado, queda pendiente dilucidar si todos estos fragmentos corresponden a uno o a varios códices. 


\begin{tabular}{|c|c|c|c|c|}
\hline & $\begin{array}{l}\text { abondado. e al } \\
\text { que no ha; toller } \\
\text { | lan aquello que } \\
\text { ouiere. }\end{array}$ & $\begin{array}{l}\text { que tiene será quj- } \\
\text { tado }\end{array}$ & & $\begin{array}{l}\text { habet et quod ha- } \\
\text { bet auferetur ab eo }\end{array}$ \\
\hline Lc 19: 27 & $\begin{array}{l}\text { Traet me mios elne- } \\
\text { migos que non } \\
\text { quisieron que yo } \\
\text { regnasse sobre- } \\
\text { llos; e matat los } \\
\text { delante mi. }\end{array}$ & $\begin{array}{l}\text { mas mjs enemj- } \\
\text { gos aquellos que } \\
\text { qujsieron que non } \\
\text { Regnase sobre } \\
\text { ellos traeldos aca } \\
\& \text { mataldos de- } \\
\text { lante mj }\end{array}$ & $\begin{array}{l}\text { Enpero aduzid } \\
\text { acá los mis ene- } \\
\text { migos, los cuales } \\
\text { non quesieron } \\
\text { que reinase so- } \\
\text { br'ellos, } e \text { matal- } \\
\text { dos ante mí }\end{array}$ & $\begin{array}{l}\text { Verumtamen ini- } \\
\text { micos meos illos } \\
\text { qui noluerunt me } \\
\text { regnare super se } \\
\text { adducite huc et } \\
\text { interficite ante } \\
\text { me }\end{array}$ \\
\hline Lc 10: 11 & $\begin{array}{l}\text { que acercar sa el } \\
\text { regno de dios }\end{array}$ & $\begin{array}{l}\text { Que se açerco el } \\
\text { Regno |de dios }\end{array}$ & $\begin{array}{l}\text { Acercase }[\ldots]\left[\mathrm{rei}_{-}\right. \\
n] \mathrm{o} \text { de Dios }\end{array}$ & $\begin{array}{l}\text { quia adropinqua- } \\
\text { vit regnum Dei }\end{array}$ \\
\hline
\end{tabular}

\subsection{Relación entre la traducción de la Catena aurea y el texto bíblico}

Cuestión intrigante es si el texto bíblico contenido en el bifolio del AHN se corresponde con el texto de las citas bíblicas que pueden identificarse en la traducción de la Catena aurea de santo Tomás. La respuesta es afirmativa solo parcialmente, lo que apunta a que la traducción de la Vulgata y de la Catena aurea se pudo llevar a cabo de forma independiente. Como se puede apreciar en el cotejo de ambos textos, existen diferencias (señaladas en negrita) entre el texto bíblico y la traducción de la Catena. Algunas de ellas son leves variantes discursivas (actualización del artículo, presencia/ausencia de pronombre clítico), pero otras implican diferencias léxicas (reino de los cielos : regno de Dios; rrafez cosa : rafez; que non tome : que non resçiba) o cambios de orden sintáctico (es pasar el camello por el forado : es el camello pasar por el forado) que podrían reputarse como argumento para establecer que la traducción de la Catena aurea y la del romanceamiento bíblico inserto en ella son dos textos independientes y no se tradujeron de manera simultánea.

\begin{tabular}{|c|c|c|}
\hline Versículo & AHN (texto bíblico) & AHN (comentario Catena) \\
\hline Lc 18: 24 & $\begin{array}{l}\text { Jesucristo veyendo a él triste dixo } \\
\text { que grave mientre entrarán en } e \text { l rei- } \\
\text { no de los cielos los que han averes }\end{array}$ & $\begin{array}{l}\text { E Jesucristo veyendo a él triste } \\
\text { dixo que grave mientre entrarán en } \\
\text { el regno de Dios los que an averes }\end{array}$ \\
\hline
\end{tabular}




\begin{tabular}{|c|c|c|}
\hline Lc 18: 25 & $\begin{array}{l}\text { ca más rafez cosa es pasar el ca- } \\
\text { mello por el forado de la aguja que } \\
\text { el rico entrar en } e \text { l regno de Dios; }\end{array}$ & $\begin{array}{l}\text { ca más rafez es el camello pasar } \\
\text { por el forado del ag aguja que el } \\
\text { r[ico] [...] [entr]ar en el regno [...] }\end{array}$ \\
\hline Lc 18: 26 & $\begin{array}{l}e \text { dixieron los que lo oían: “¿E} \\
\text { quién puede ser salvo?" }\end{array}$ & $\begin{array}{l}{[d] \text { ixieron los que oían: ¿E quién }} \\
\text { puede ser sal[vo]? }\end{array}$ \\
\hline Lc 18: 27 & $\begin{array}{l}E \text { dixo a ellos: "Las cosas que non } \\
\text { pueden ser ante los omnes pueden } \\
\text { ser ante Dios" }\end{array}$ & $\begin{array}{l}E \text { dixo a ellos: "Las co[sas] [que] } \\
\text { non pueden ser ante los omnes pue- } \\
\text { den }[\text { ser }][a] \text { nte Dios" }\end{array}$ \\
\hline Lc 18: 28 & $\begin{array}{l}E \text { dixo Sant Pedro: "Ahé, nós dexa- } \\
\text { mos todas las cosas } e \text { seguímoste". }\end{array}$ & $\begin{array}{l}E \text { dixo Sant Pedro: "Ahé, dexamos } \\
\text { todas las cosas" }\end{array}$ \\
\hline Lc 18: 29 & $\begin{array}{l}E \text { él díxoles: "Dígovos por cierto } \\
\text { que non hay ninguno que haya dexa- } \\
\text { do la casa o los parientes o los her- } \\
\text { manos o la muger o los fijos o los } \\
\text { canpos por el regno de Dios }\end{array}$ & $\begin{array}{l}\text { Dígovos por cierto: non hay nin- } \\
\text { guo que haya dexado la casa o los } \\
\text { parientes o los parientes o los her- } \\
\text { manos o la muger o los fijos o los } \\
\text { canpos por el regno de Dios }\end{array}$ \\
\hline Lc 18: 30 & $\begin{array}{l}\text { que non tome mucho más en este } \\
\text { tienpo } e \text { en } e \text { l sieglo avenidero la } \\
\text { vida perdurable. }\end{array}$ & $\begin{array}{l}\text { que non reciba mucho más en este } \\
\text { tienpo } e \text { en } e \text { l sieglo avenidero vi- } \\
\text { da perdurable }\end{array}$ \\
\hline Lc 19: 28 & $\begin{array}{l}\text { TESTO Esto dicho iva Jesucristo an- } \\
\text { te ellos } e \text { subió a Jerusalem. }\end{array}$ & $E$ esto $\operatorname{dich}[o][\ldots]$ ellos $e \operatorname{sub}[\ldots]$ \\
\hline Lc 19: 29 & $\begin{array}{l}E \text { fecho es como llegase a Betha- } \\
\text { nia al monte que es llamado de las } \\
\text { olivas enbió dos disciplus suyos }\end{array}$ & $\begin{array}{l}\text { "[...] como llega }[\text { se }]<\ldots>[\ldots][\text { Be }- \\
\text { thta]ie } e \text { a Betha[niam }]<\ldots>\text { monte } \\
\text { que es }[\ldots] \text { de las olivas, sus dos } \\
\text { disc[...] }\end{array}$ \\
\hline
\end{tabular}

Si comparamos el texto neotestamentario del romanceamiento y las citas bíblicas presentes en la traducción de la Catena aurea entre sí y con la Vulgata, se puede apreciar que ambos parecen ser traducciones diferentes, ya que la traducción de la Catena se muestra más apegada a los lemas latinos de la Vulgata:

\begin{tabular}{|l|l|l|l|}
\hline Versículo & \multicolumn{1}{|c|}{ Vulgata } & AHN (texto bíblico) & AHN(comentario Catena) \\
\hline Lc 18: 24 & Regnum Dei & reino de los cielos & regno de Dios \\
\hline Lc 18: 25 & facilius & más rafez cosa es & más rafez es \\
\hline Lc 18: 26 & dixerunt qui audiebant & dixieron los que lo oían & {$[d]$ ixieron los que oían } \\
\hline
\end{tabular}




\begin{tabular}{|l|l|l|l|}
\hline Lc 18: 28 & $\begin{array}{l}\text { ecce nos dimisimus om- } \\
\text { nia }\end{array}$ & $\begin{array}{l}\text { Ahé, nós dexamos todas } \\
\text { las cosas }\end{array}$ & $\begin{array}{l}\text { Ahé, dexamos todas las } \\
\text { cosas }\end{array}$ \\
\hline Lc 18: 30 & $\begin{array}{l}\text { et non recipiat multo } \\
\text { plura }\end{array}$ & $\begin{array}{l}\text { que non tome mucho } \\
\text { más }\end{array}$ & $\begin{array}{l}\text { que non reciba mucho } \\
\text { más }\end{array}$ \\
\hline Lc 19: 29 & $\begin{array}{l}\text { cum adpropinquasset ad } \\
\text { Bethfage et Bethania ad } \\
\text { montem }\end{array}$ & $\begin{array}{l}\text { como llegase a Bethania } \\
\text { al monte }\end{array}$ & $\begin{array}{l}\text { como llega[se }][\ldots] \mid[\ldots] \\
{[\text { Bethta }] \text { ie } e \text { a Betha- }} \\
{[\text { niam }[\ldots] \text { monte }}\end{array}$ \\
\hline
\end{tabular}

La diferencia de mayor calado entre el romanceamiento bíblico y la traducción de la Catena se encuentra en la ausencia de la referencia al lugar de Bethfage que aparece en la Vulgata (et factum est cum adpropinquasset ad Bethfage et Bethania, Lc 19: 29); referencia que solo figura en la traducción de la Cate$n a$ pero no en el texto bíblico de AHN (sí aparece en E6 y en los Evangelios de Lucena). Así las cosas, mi impresión es que el códice del AHN (A), al ser un ejemplar suntuario, copia un texto anterior (B) de la Catena aurea. Este texto B utilizó en su composición un romanceamiento del evangelio de San Lucas (C) preexistente. Por ello, A/B y C no deberían tratarse unitariamente, ya que son textos distintos; $\mathrm{C}$ sería anterior a $\mathrm{A} / \mathrm{B}$. La brevedad del fragmento conservado impide establecer cuál es la posible distancia lingüística y cronológica entre $\mathrm{C}$ y $\mathrm{A} / \mathrm{B}$. Con todo, la comparación entre el romanceamiento bíblico y la Catena no demuestra con total seguridad que procedan de traducciones diferentes, ya que las diferencias entre ambos podían haberse heredado del modelo latino que utilizó el traductor del texto de AHN.

\subsection{El modelo latino de la traducción de la Catena aurea del AHN}

Es muy posible que el modelo latino del que tradujo AHN fuera una Catena aurea con el texto bíblico incorporado, similar al MSS/214 de la $\mathrm{BNE}^{49}$. Los dos códices latinos de la Catena aurea con los que mayor similitud material guarda el fragmento del AHN son, por un lado, un manuscrito del Archivo de la Corona de Aragón que conserva fragmentos de una Catena en latín del s. XIV unida como hoja de guarda de un volumen de sermones de Inocencio III y

${ }^{49}$ Se trata de un manuscrito latino titulado Catena aurea in Evangelia secundum Mathaeum et Marcum, s. XIII, 168 fols. 2 col. 50 lín. perg. 360 x 240 mm. gótica, con miniaturas, títulos, versales y calderones en rojo (olim Felipe V). El texto bíblico figura, como en el bifolio del AHN, en una columna de cuerpo menor claramente separada del comentario. Las imágenes de este códice están disponibles en la Biblioteca Digital Hispánica de la BNE <http://bdh-rd.bne.es/ viewer.vm?id=0000006501\&page $=1>$. 
cuyo parecido en cuanto a rúbricas, letra y disposición del texto con el bifolio del AHN es muy elevado ${ }^{50}$; por otro lado, también el ms. lat. 638 de la BNF, que contiene la parte de la Catena correspondiente al evangelio de Lucas, en latín, del s. XIII presenta la misma disposición que el fragmento del AHN (vid. fol. 1 va-vb y fol. 156ra-rb) ${ }^{51}$. En cualquier caso, la coincidencia de la distribución columnar del texto del AHN con la de varios manuscritos latinos medievales de la Catena es un argumento más a favor de la identificación de AHN como una traducción de la Catena aurea de santo Tomás.

Puesto que las traducciones y las copias suelen reproducir su modelo en la distribución material del texto, sería teóricamente posible identificar el modelo latino de AHN; pero no existe, por desgracia, un repertorio de los manuscritos latinos de la Catena aurea conservados en las bibliotecas peninsulares ${ }^{52}$. A priori, una vez reunidos los ejemplares conocidos ayudaría a la identificación exacta del modelo el hecho de que ese códice latino contuviera el mismo yerro que AHN en el capítulo 5 del comentario de santo Tomás al capítulo XVIII de

${ }^{50}$ La referencia concreta del testimonio es Barcelona, ACA, Ripoll, 36, Sermones Innocencii pape; y su Tractatus de elemosina s. XIV. También del s. XIV es un folio de guarda adosado a este códice que contiene fragmentos de un manuscrito con el inicio de la Catena aurea super Iohannem, ff. 1ra-3vb, 4ra-rb. En una nota del s. XIV puede leerse: Iste liber est conventus Rivipulli: ponatur in libraria $\mathrm{f}$. 1r.. Contiene el principio del evangelio de san Juan, en latín y podría ser el resto de un manuscrito latino de la Catena aurea probablemente íntegro. Esta nota del s. XIV hace referencia al manuscrito de la Catena aurea, del cual solo quedan algunos folios, no a los Sermones. Ambos códices circularían independientemente hasta el momento en el que el primero se desmembró y en el s. XIX fue encuadernado en un solo volumen con la otra obra. Esto pudo suceder también antes y darse el caso de que en el s. XIX únicamente se sustituyera la antigua encuadernación por una nueva. Los dos textos se unieron por compartir tamaño y por tratar de materias semejantes. Presenta el mismo sistema de mise-en-page que el ms. del AHN, pero con el evangelio repartido en pasajes muy breves (pocas palabras) en subcolumna, con el comentario al lado; en los ff. 3vb y 4rb el pasaje es más amplio y está dispuesto de modo decorativo (en f. $3 v b)$ en la subcolumna. Las imágenes pueden consultarse en PARES (http://pares.mcu.es).

${ }^{51}$ Este códice perteneció en el s. XV al obispo de Béziers. La disposición y extensión del texto bíblico es idéntica en este códice y en el fragmento de AHN: ambos aíslan del comentario justamente la misma sección del capítulo 18 de Lucas, esto es, los versículos 24-30 (BNF ms. lat. 638 , fol. 156r), e idéntica es también la fragmentación del capítulo 19, en el que ambos seleccionan justamente el mismo intervalo de los versículos 18-36 (BNF ms. lat. 638, fol. 162r-v). Las imágenes del códice se encuentran disponibles en GALLICA (http://gallica.bnf.fr) bajo el título S. Thomas de Aquino, Catena aurea in Evangelium Lucae, 1201-1300.

52 Aunque no he hecho una búsqueda exhaustiva, no puedo añadir más testimonios manuscritos que el MSS/214 de la BNE y el fragmento del ACA. No encuentro noticia de otros ejemplares manuscritos en los catálogos de la BNE, de la Biblioteca de El Escorial y de la Biblioteca Histórica de la Complutense. Sí abundan, empero, los testimonios latinos impresos de la Catena aurea: solo de la BNE pueden citarse los siguientes ejemplares incunables, cuyas referencias debo a Gemma Avenoza: BNE INC/1289; INC/1290; INC/1596; INC/1747; INC/1880; INC/337; INC/1266. En Gallica aparecen no menos de 140 testimonios manuscritos de la Catena aurea, entre los que descuellan el ya citado ms. lat. 638 de la BNF y el ms. 5 de la Bibliothèque de Louviers, Catena aurea in Matthaeum, s. XV, que perteneció a la biblioteca de los reyes de Aragón en Nápoles. 
Lucas, al citar a Teofilacto donde corresponde Cirilo o, al igual que AHN, no presentara la referencia a Bethfage en Lc 19: $29^{53}$.

\subsection{Conclusiones acerca del texto}

Creo haber probado que el bifolio del AHN contiene una traducción romance de la Catena aurea de Tomás de Aquino, única conocida en Castilla hasta la fecha y a la que habría que sumar la contenida en los mss. 83 y 108 de Toledo si se demuestra que efectivamente son también traducciones de este mismo texto. La singularidad del fragmento del AHN no acaba aquí, puesto que además de la traducción de la Catena ha conservado dos secciones del NT que transmiten los versículos 18: 24-30 y 19: 28-36 del Evangelio según Lucas, también en romance. Este romanceamiento bíblico reviste especial importancia por cuanto no coincide con ninguno de los romanceamientos bíblicos del NT conocidos hasta la fecha (E6 y Martín de Lucena). Así las cosas, cabe postular la existencia de dos textos diferentes en el bifolio del AHN: (a) una traducción de la Catena aurea en romance; (b) un romanceamiento de parte del Evangelio de san Lucas.

\section{CRITERIOS DE TRANSCRIPCIÓN}

Para la edición del texto he optado por una presentación crítica que coincide en lo sustancial con los criterios de la red CHARTA ${ }^{54}$. Marco con una barra

\footnotetext{
${ }^{53}$ No debe descartarse tampoco que la confusión de Cirilo por Teofilacto y la ausencia de la referencia a Bethfage no guarden relación alguna con su modelo, sino que sean simples errores en el proceso de copia: las rúbricas en rojo se copiaban normalmente una vez se había acabado de copiar el texto, a veces del mismo original y las más a partir de notas que los copistas dejaban en los márgenes, por lo que la confusión Teófilo / Cirilo en el mismo bifolio no resultaría extraña; en cuanto a la ausencia de Bethfage en el texto bíblico de AHN, podría tratarse simplemente de una omisión deliberada del copista ante un nombre que no entendía, o bien pudo producirse por un salto de igual a igual dada la similitud entre Bethania y Bethfage, topónimos que coinciden en su segmento inicial. En contrapartida, la localización de ejemplares de la Vulgata de los que se pueda demostrar su circulación en Castilla y en los que no se encuentre la referencia a Bethfage en Lc 19: 29 sustentaría la hipótesis de que se utilizó un romanceamiento bíblico anterior (no muy anterior, en cualquier caso) para el texto bíblico de AHN.

$54<\mathrm{http}: / / \mathrm{www}$.redcharta.es/criterios-de-edicion/>. Una transcripción paleográfica del texto bíblico (no del comentario) y las imágenes en color del fragmento conservado estará pronto disponible en el portal Bibliamedieval (Enrique-Arias y Pueyo, 2008). He unificado el uso de mayúsculas y minúsculas y he ajustado la puntuación al uso actual. Prescindo de las grafías dobles y mayúsculas sin valor fonológico (-mm-, -ff-, $r r$-, o R-) y regularizo $j-i-y$ y $u-v$ según tengan valor consonático $(y, j, v)$ o vocálico $(i, u)$. Regularizo la $h$ - en las formas del verbo haber. Deshago las amalgamas y uno palabras que estaban separadas según los usos medievales. Siguiendo la práctica habitual en
} 
vertical (|) el cambio de renglón, que va entre espacios salvo si el cambio conlleva el corte de una palabra. Marco en versales las rúbricas del manuscrito. Dadas las dificultades para reproducir la distribución columnar del manuscrito, edito por separado el texto bíblico del comentario, ajusto el primero a la numeración por versículos de la Vulgata Stuttgartensia (Weber y Gryson, 2007) y el segundo a la disposición textual adoptada por la edición de la Catena aurea de Guarienti (1953), de quien adopto la capitulación y la denominación latina de los comentaristas, que encuadro entre corchetes [ ]. La edición de Guarenti (1953) me ha servido de ayuda también para ajustar la puntuación del comentario, así como para apoyar la reconstrucción del texto en aquellas secciones dañadas por la guillotinación del manuscrito. Indico con puntos suspensivos y paréntesis angulares $<\ldots . .>$ el texto faltante por la mutilación de los folios. Suplo con corchetes [] que enmarcan la palabra reconstruida aquellas lagunas del texto que pueden subsanarse con el apoyo de la Vulgata o de la Catena aurea; si no acierto en la reconstrucción lo señalo con $[\ldots]^{55}$. Resuelvo con paréntesis angulares $<>$ las haplografías del texto. El primer folio resulta casi ilegible, a excepción de una pequeña porción, por lo que he optado por transcribir solo el fragmento correspondiente al texto bíblico, donde sí se puede apreciar continuidad textual (gracias en parte también al apoyo de la Vulgata), pero no he transcrito las escasas palabras de la traducción de la Catena que todavía resultan legibles ${ }^{56}$.

\section{EDICIÓN DEL TEXTO}

[CATENA AUREA. COMMENTARIUM S. THOMAE CAPUT XVIII] [4]

\section{[TEOPHYLACTUS]}

[f. 1ra] <...> otras vertudes, $e$ por ende dize " $E$ ven $e$ sígue|me", que quier dezir: en las otras cosas sey mi | disciplo $e$ cada día me siguirás.

\footnotetext{
la edición de textos antiguos, resuelvo como enclíticos los pronombres. Desarrollo en cursiva las abreviaturas y letras voladas, transcribo el signo tironiano como $e$ (en cursiva) y reparto ese sigma y zeta según corresponda etimológicamente. Resuelvo siempre las abreviaturas del nombre del hijo de dios como Jesucristo y como Jerusalem las abreviaturas para este topónimo.

${ }^{55}$ Limito mi reconstrucción del texto al nivel de la palabra: si una palabra aparece truncada pero conserva alguna de sus letras, enmiendo entre corchetes las letras faltantes. No reconstruyo, en cambio, palabras enteras a pesar de contar con el apoyo del texto subyacente de santo Tomás, dada la imposibilidad de conocer qué palabra exacta en romance eligió el traductor para verter el texto latino.

56 Tal vez con una lámpara ultravioleta y el empleo de técnicas avanzadas de tratamiento de imagen hubiera podido recuperar más texto de este último folio, pero el conservador jefe de la sección de códices del AHN me denegó el empleo de lámparas de luz.
} 


\section{[CYRILLUS]}

CERILLO. Ca qu'el | príncipe [borroso]ndo odre viejo, non fue cabien|te para recibir vino nuevo, mas es rom|pido por tristeza; onde síguese "Entristecid|o es él por estas cosas oídas, porque era m|uy rico".

\section{[BASILIUS]}

SANT BASILIO. El mercador non se entri|stece en las ferias preteando las cosas | que ha ganado, las cosas que ha son convenibl|es a él; e tú eres entristecido $e$ das polvo por | que ganes la vida bien aventurada.

\section{[Evangelio según san Lucas]}

[f. 1ra] $18{ }_{24]}$ TESTO Jesucristo ve|yendo a él tris|te dixo que g|rave mientre entr|arán en $e$ l reino de | los cielos los que han | averes, ${ }_{25]}$ ca más ra|fez cosa es pasar el | camello por el fora|do de la aguja que el | rico entrar en $e$ re|gno de Dios; ${ }_{26]} e$ dixie|ron los que lo oían: “ ¿E | quién puede ser salvo?” ${ }_{271} E \mid$ dixo a ellos: "Las cos|as que non pueden ser | ante los omnes pueden | ser ante Dios". ${ }_{281} E$ dixo | Sant Pedro: "Ahé, nós | dexamos todas las | cosas $e$ seguímos|te". ${ }_{29} E$ él díxoles: "Dígo|vos por cierto que non | hay ninguno que haya d|exado la casa o los $\mid$ parientes o los her $\left.\right|^{[\text {f. lrb] }}$ manos o la muger $\mid$ o los fijos o los campos por el regno | de Dios ${ }_{30]}$ que non tome | mucho más en este | tiempo $e$ en $e$ lieglo ave|nidero la vida perdu|rable".

\section{[CATENA AUREA. COMMENTARIUM S. THOMAE CAPUT XVIII]}

[5]

\section{[TEOPHYLACTUS]}

TEÓFILO. | E porque el rico fue en|tristecido, oído el ech|amiento de las riquez|as, fabló el señor m|aravillosamientre, | ca es dicho: "E Jesucristo | veyendo a él triste | dixo que gravemien|tre entrarán en el reg|no de Dios los que an | averes". Non dize: non | podrán ellos entrar, | mas dize "grave|mientre"; ca pueden | por las riquezas gan|ar las cosas somer|anas, mas es grave, | ca más tenederas | son las riquezas que el | engludo; $e$ apenas | es arrancado preso $^{57}$ d'e|llas más luego ju|dga esto así como n|on podible, [c]omo di|ga: "ca más rafez $\mid$ es el camello pasar por el forado del ag $\left.\right|^{[\text {f. } 1 \text { rb] }}$ aguja que el $\mathrm{r}[$ ico $][\ldots] \mid[$ entr] ar en $e$ l regno <...> | el nonbre que <...> en griego ese $<\ldots>\mid$ ca sinifica el $\mid<\ldots>$ que es gamell[ $[o] \mid[\ldots]$ no $e$ en cualquier $<\ldots\rangle \mid$ que lo entienda $<\ldots>\mid$ podible. Pues así es, que es a dezir pri[...] | en verdat así sea, ca otra cosa es rico | $<\ldots>[e]$ spensero, ca el rico es el que guarda $\mathrm{la}[s]<\ldots>\mid[$ riquez]as para sí, mas el despensero el que las tie $[n e]<\ldots>\mid[\ldots]$ bra de todos.

\footnotetext{
${ }^{57}$ Texto latino: et vix evellitur animus occupatus ab eis.
} 


\section{[CHRYSOSTOMUS IN IOANNEN HOM. 18]}

SANT GRISÓSTOMO. Et por $\mid<\ldots>[$ A $]$ braham posedía riquezas para los $\mathrm{p}[$ obres $]<\ldots>$ los que las han derechureramientre $<\ldots>\mid$ tomándolas de Dios dispensan en $<\ldots>\mid$ $[$ man]dados divinales, $e$ los que las gana $[n]<\ldots>\mid$ Dios eso mismo fazen espendiend[...] $\mid$ contrario dándolas a las putas $e$ a $<\ldots . .>\mid$ gastadores, o ascondientes las $\mathrm{e}[\ldots] \mid e$ non dando alguna cosa a los mengua $[n t e s]^{58}<\ldots>\mid[P]$ ues así es, non defiende ser enriqueci[...] | servidos por riquezas quiere que en los $<\ldots .>\mid$ usemos d'ellas $e$ non que las guardemos. <...> | [...]uo pertenece guardar, mas al señor de[...] $\mid$ Si quesiese guardarlas non las diera a los $\langle\ldots\rangle \mid$ mas dexáralas yazer en tierra.

\section{[THEOPHYLACTUS]}

TEÓFIL $[O] . \mid<\ldots>$ mientes a aquello que dize el rico por cie $[r t o] \mid<\ldots>$ poder ser salvo $e$ los que han las riquezas $<\ldots . .>\mid$ mientre, así como si diga: el rico, el cual <...> de las riquezas, $e$ es servido d'ellas non será $<\ldots>\mid$ por razón de la humanal flaqueza; ca | [...]ça el [dia]blo arrancar nos mientra a[...] | riquezas, $e$ grave cosa es fuir las desç[...] $\mid<\ldots>$ d'él. Et por tanto buena es la pobreza car[...] | de tentación.

\section{[CHRYSOSTOMUS]}

TEÓFILO. Ca non hay ningu[...] | [borrón]cho de las riquezas, sofriendo el alma <...> | daño de pobreza el alma abondando e[...] | [rique]zas. $E$ si es señal de enrequeciente se [...] | [..]ver mengua de ningúa cosa $e$ señal de pobreç[...] ${ }^{[f . ~ 1 v a] ~[. . .] n e n g u a ~ m a n i f i e s t a ~}$ cosa es que ser $\mathrm{m}[\ldots] \mid[\ldots]$ bre faze más enriquecer, ca más re[fez]|[m]ientre alguno menospreciará las ri[quezas] | en pobreza que en riquezas, ca non es | [cob]dicia que se amanse por más aver, mas | [...]o suele ser más encendida segunt el $<\ldots>\mid$ cuando toma mayor manjar. Et las co[...] | [...]on vistas ser malas, comunales son $<\ldots>\mid$ [...]gua $e$ las que son de riquezas son propias.

[AGUSTINUS DE QUAEST. EVANG 2,47]

SANTO AGOSTÍN DE LAS CUESTIONES DEL EV[ANGELIO]. | [...]sus así es, al rico llama cobdicioso de $\mid$ [riquez] as tenporales $e$ ensoberveciéndese ${ }^{59}$ de ta[...] $\mid[l o]$ s pobres son contrarios a estos ri $[\cos ]|<\ldots\rangle$ el $[e]$ spíritu de los cuales es el regno de los $<\ldots\rangle \mid$ Mezcladamientre más rafez es | [pasi]ón sofrir que los amadores del sieglo, po[...] | convertidos a Jesucristo. Ca por nombr $[e]|<\ldots\rangle[c a]$ mello quiso él ser él entendido, ca de $\operatorname{gr}[a d o]<\ldots>\mid[\ldots]$ villado sofrió las cargas de la nuestra | [gra]vedat. Et por el fecho $\operatorname{sig}[n]$ ifica punçam[iento] $\mid e$ por los punçamientos $\operatorname{sig}[n]$ ifica los $\mid[\ldots] s$ rescibidos en la pasión $e$ el forad $[o] \mid<\ldots>[a]$ guja dize quexura de pasión.

\footnotetext{
58 Texto latino: egenis vero nihil impedentes.

59 Texto latino: Divitem ergo hic appellat cupidum rerum temporalium, et de talis superbientem.
} 


\section{[CHRYSOSTOMUS IN MATTHAEUM HOM. 64]}

SANT GRISÓS[TOMO]. $\mid$ E este sermón así como pesado traspa[sava] $\mid<\ldots>$ vertud de los discípulos, onde sígu[ese $] \mid<\ldots>$ "[ $d]$ ixieron los que oían: «¿E quién puede ser sal[vo]?»". | Esto dixieron los discípulos non temi $[\ldots] \mid<\ldots>[d]$ e sí, mas de todo el mundo.

\section{[AGUSTINUS (UT SUPRA)]}

SANT AGOS[TíN] | LAS CONCORDANÇAS. Et como sin comparaci[ón] <...> | mayor la conpañía de los pobres la $<\ldots>\mid$ ricos perdidos pueda ser salva, enden $<\ldots>\mid$ todos los que aman las riquezas aun si $<\ldots>\mid[p]$ uedan ser ganadas ser dadas en cuen $[t a]<\ldots>\mid$ $[l]$ os ricos. Síguese: " $E$ dixo a ellos: «Las co[sas] | [que] non pueden ser ante los omnes pueden [ser] |[a]nte Dios»". La cual cosa non es a entender | [co]mo si el rico con cobdicia $e$ sobervia hay $[a]<\ldots>\mid[e n]$ trar en $e$ l regno de Dios, mas podible $\mid<\ldots>$ $[D]$ ios que sea que de la cobdicia $e$ sobervia se | [convi]erta a la caridat $e$ a la omildat.

\section{[TEOPHYLACTUS]}

TE[|[f. 1vb] ÓFILO. Pues así es ante los omnes, la entención | de los cuales se rastra a las cosas terrenales, | non es podible la salut segunt dicho es, $e$ cua|nto a Dios, es podible. $\mathrm{Ca}$ como el omne ha $/$ consejero a Dios $e$ las justificaciones $e$ las do|trinas haya embevido $e$ aun llame la su $\mid$ ayuda, este ser fecho podible.

\section{[CYRILLUS]}

CERILLO. $E$ con|veniblemientre el rico, como haya men|ospreciado todas las cosas, esperará recom|pensación; mas el que ha pocas cosas, renunció | a ellas; que convenía a él demandar esperando. | Onde síguese: " $E$ dixo Sant Pedro: «Ahé, dex|amos todas las cosas»". Añade Sant Mateo: | "Pues así es, ¿qué será a nós?”.

\section{[BEDA]}

BEDA. Así como si | diga: "Fezimos lo que mandaste, ¿e qué galardón | nos darás?". E porque non cumple tan solamientre | dexar todas las cosas ayunta lo que es aca|bado diziendo: "E seguímoste".

\section{[CYRILLUS]}

CERILLO. E mester | es dezir aquello, que los renunciantes a pocas | cosas, cuanto pertenece al propósito $e$ a la obedi|encia, los usantes de los eguales talantes | son colgados por egual manera con los a|bastados, mientra que de grado dizen el echa|miento de las cosas que han; onde síguese: "Dí|govos por cierto: non hay ningúo que haya de|xado la casa o los parientes o los parien|tes o los hermanos o la muger o los fijos | o los campos por el regno de Dios que non | reciba mucho más en este tienpo $e$ en $e$ l sieg|lo avenidero vida perdurable". Alça todos | los oyentes a la esperança muy agrada|ble, prometiendo por juramento mientra | dize: "por cierto"; ca llamando la dotrina | divinal el mundo a la fe de Jesucristo, por ven|tura algunos, veyentes non fie- 
les a sus | parientes, non quisieron turbarlos veniendo | a la fe, et semejable es la razón de los $\mid$ otros hermanos. $E$ desampararo ${ }^{60}$ por cierto el | padre $e$ la madre $e$ menosprecian el amor $\mid$ de todo el parentesco por el amor de Dios.

\section{[CATENA AUREA. COMMENTARIUM S. THOMAE CAPUT XIX]}

[2]

[AMBROSIUS]

[f. 2va] cuales así como debdores desgastadores perdi|eron las cosas que havían tomado. En aquellos dos | siervos, los cuales ganaron, son señalados los $\mid$ pocos los cuales por dos vezes son embiados | a los labradores de la viña, en los otros jud|íos todos. Ca síguese: " $E$ dixiéronle: «Señor, die|z dineros ha»". $E$ por ventura esto es derecho. Somete: "Dígovos por cierto que será dado a todo | aviente".

\section{[TEOPHYLACTUS]}

TEÓFILO. Ca como haya acrecen|tado diez doblado, manifiesta cosa es que dob|lando más cosas serán fechas a los pueblos | ocasión de ganancias por el señorío. Mas del perezoso $e$ del vagaroso, el cual non se esforçó a | acrecentar lo que havía tomado, será tirado a|quello que ha; onde se sigue: " $E$ al que non ha será to|mado lo que ha", que non venga al siervo ${ }^{61}$ dominical co|mo pudiese ser dado a los otros, $e$ ser<á> acrecen|tado. Et estas cosas non tan señeramientre al $\mid$ sermón $e$ a la dotrina se deven referir, mas au|n a las vertudes morales; ca en estas cosas | nos da Dios las sus gracias, recreciendo a est|e por ayuno e $<\mathrm{a}>$ aquel por oración, e al otro por man|sedunbre o por omildat; en las cuales cosas si | veláremos, acrecentámoslas, $e$ si nos efri|amos, amatámoslas. Depués somete de los | adversarios: "Empero aduzid acá los mis ene|migos, los cuales non quisieron que reinase so|br'ellos, $e$ mataldos ante mí".

\section{[AGUSTINUS (UT SUPRA)]}

SANTO agostín de Las Cuestiones del evangelio. Por la cual cosa si|nifica la non piadat de los judíos, porque se non | quesieron convertir a él.

\section{[TEOPHYLACTUS]}

TEÓFILO. Los cuales dio a la $\mid$ muerte embiándolos en $e$ l fuego de fuera, m|as aún en $e$ ste mundo son muerto[s] llorosamien|tre de la compaña de los romanos.

\section{[CHRYSOSTOMUS]}

SANT GRISÓSTO|MO. Estas cosas conviene contra unos here|ges llamados marcionistas, ca dize Jesucristo: | "Traed los mis enemigos $e$ mataldos delan|te mí"; como empero

${ }^{60}$ Sin lineta en el manuscrito, desapararon.

${ }^{61}$ La palabra siervo debe encubrir una mala lectura del texto de la Vulgata, que trae censum, o quizá obedezca a un error de copia si suponemos que el texto bíblico es la copia en limpio de un borrador romance previo en el que tal vez figurara la forma *ienso. 
ellos digan bueno a Jesucristo $\mid e$ al dios del Testamento Viejo malo. $E$ pare|ce que unas cosas faze el padre que el fijo: | ca el padre embía la conpañía a la viña, $e$ el fijo | faze los enemigos delante él ser atormen|[ ${ }^{[f .}{ }^{2 \mathrm{vb}]}$ tados. Et esta semejança que se escrive $\mathrm{e}[n] \mid$ [evan]gelio de sant Lucas otra es que aquella que s[...] | [...]ta en el evangelio de sant Mateo, de $\operatorname{lo}[s]<\ldots\rangle \mid$ que aquí por cierto del un cabdal tomad[...] $|<\ldots$.$\rangle desvaria-$ das las ganancias, ca del vi[...] | tomado, éste ofreció cinco marcos, e a[quel] $<\ldots>\mid$ mas en $e$ l de Mateo el contrario, ca $<\ldots>\mid$ dos, añadió dos $e$ el que cinco, otro tant $[o]$; $<\ldots>\mid$ son a ellos donados galardones des[...]

\section{[Evangelio según san Lucas]}

[f. 2vb] $19{ }_{28]}$ TESTO. Esto dicho | iva Jesucristo | ante ellos | $e$ subió a Jerusalem. ${ }_{29]} E$ fe|cho es como llega|se a Bethania al m|onte que es llamado | de las olivas embió | dos disciplus suyos ${ }_{301} \mid e$ díxoles: "Id <a> aquel ca|stiello que es contra | vós $e$ como entrar|des en él fallaredes | un pollino de la asn|a atado, sobre el cual | aún nunca estudo on|me ninguno. Desatal|do $e$ traédmelo. ${ }_{31} E$ si $\mid$ vos alguno pregun|tare por qué lo soltad|es dezilde así, que el se|ñor desea la su obra". | ${ }_{32]} E$ fuéronse los que eran embiados $e$ fallaron | así como les él dix|o el pollino estante. ${ }_{33 \mid} \mid E$ mientra que ellos $\mid$ lo soltasen dixier|on los señores d'él | a ellos: “¿Para qué desata|des el pollino?” ${ }_{34]} E$ ell[os] |[f. 2ra] $\left[\right.$ dix]ieron: "Porque él | [l]o ha mester". $\left.\right|_{35]}[$ Trax $]$ iéronlo a Jesu[Cristo $]$ | poniendo sus $\mid$ [vestidu]ras sobr'él $\mid<\ldots>$ a Jesucristo $\mid<\ldots>$ d'él ${ }_{36]} e$ él yen[do] [...]avan sus vest[iduras] | en el camino.

\section{[TITUS]}

[f. 2vb] Tiтo. | Porque avía di[cho] <...> | [Se]ñor: "Acércase | <...> [rein]o de Dios", vey[...] $\mid[\ldots]$ os a él subir $\mid$ pensavan que si $<\ldots . .>$ que començas $[e]<\ldots>\mid[$ rei $]$ no de Dios. $\mid<\ldots>$ es acabada $\mid[\ldots]$ ça en la cual e[...] $\mid<\ldots>[y]$ erros ante $\mathrm{d}[\ldots] \mid[\ldots]$ trando que hav[er] | vencido al $\mid<\ldots . .>$ le la muer[te], | a la pasión <...> | en Jerusalem o[...] | " $E$ esto $\operatorname{dich}[o]<\ldots>\mid$ ellos $e \operatorname{sub}[\ldots]$ ".

\section{[BEDA]}

BEDA. $E$ d[...] | semejança | venida d'él <...> | [...]to de la cibdat $\mid$ havían amata[...] [...]via aparec[...] | [...]tilencia en $\mid[\ldots]$ e. $E$ síguese: $\mid\langle\ldots\rangle$ "como llega[se $]|<\ldots\rangle$ $[$ Bethta]ie $e$ a Betha[niam $<\ldots . .>\mid$ monte que es $<\ldots>\mid$ de las oliva[s], | sus dos

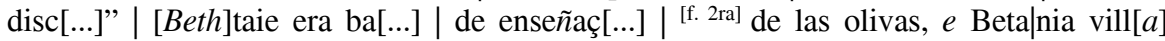
$[* * *]^{62}$

${ }^{62}$ A partir de aquí el texto se vuelve ilegible por haber sido raspado; de modo que transcribo solo el explicit del fragmento: "ala yglesia e estaua a liga[do a lo]s ligamjen[tos]" (fol. 2vb). 


\section{FINAL}

Entre los fragmentos de códices que se encuentran en el libro 1.464 del AHN se ubica un bifolio que contiene algunos restos de una copia muy cuidada de una traducción al romance de la Catena aurea de Tomás de Aquino, en la que se han incluido de forma destacada algunos versículos de un romanceamiento bíblico desconocido que contiene parte del evangelio según Lucas, traducidos de la Vulgata.

El análisis lingüístico y paleográfico del bifolio conservado apunta a que este se escribió entre 1370-1450, marco cronológico que por indicios podría acotarse incluso a 1380-1420 (la paleografía apunta más bien a 1380-1400), con todas las precauciones que impone la brevedad del testimonio conservado, carente de data tópica y cronológica. La lengua del texto sugiere que el traductor podría ser originario de Miranda de Ebro o de alguna comarca limítrofe, ya que, en conjunto, presenta soluciones propias del castellano norteño de finales del s. XIV o principios del s. XV, así como algunos rasgos que muestran solidaridades léxicas y morfosintácticas con las variedades del noreste de Burgos, Álava, Navarra y Rioja.

El análisis textual y exegético al que he sometido al testimonio revela también la falta de conexión de los versículos bíblicos de AHN tanto con el romanceamiento bíblico del NT de la Biblia prealfonsí (ms. Esc. I-I-6, s. XIII) como con el de los Evangelios y epístolas paulinas que Martín de Lucena tradujo para el Marqués de Santillana (BNE MSS/9556 de la BNE, s. XV), únicos testimonios medievales conocidos de Evangelios en romance traducidos de la Vulgata. La Catena aurea contenida en AHN saca a la luz la existencia de una traducción romance de la que se desconocía su existencia en Castilla, y pone de relieve la presencia de un interés en círculos cristianos y en un contexto romance por la exégesis y la lectura de la biblia. En este sentido, la existencia de esta traducción de la Catena aurea de santo Tomás en el bifolio del AHN enlaza este testimonio con los códices mss. 83 y 108 de la Biblioteca de Castilla-La Mancha que, si no me equivoco, contienen también una traducción de la Catena aurea de los evangelios de Mateo y Juan; lo que demuestra la circulación y el interés por el texto de santo Tomás en la Castilla de finales del s. XIV, aspecto de la historia de la exégesis bíblica hispana que está por estudiar.

La brevedad del fragmento del AHN impide, por desgracia, dar respuesta a una serie de interrogantes capitales para la génesis del códice al que pertenecía el fragmento de AHN y su posición dentro de la cadena de romanceamientos bíblicos y comentarios de las Escrituras en la Edad Media: ¿fue un noble su promotor? ¿cuál es la relación exacta entre este romanceamiento y el monasterio de San Miguel del Monte? ¿existió el texto bíblico de AHN de manera independiente de la traducción de la Catena aurea antes de copiarse en el códice 
del AHN? ¿guarda alguna relación la traducción de la Catena aurea de AHN con el texto contenido en los mss. 83 y 108 de la Biblioteca de Castilla-La Mancha? A falta de respuestas para estas cuestiones, se puede saludar al fragmento del AHN como la primera copia identificada de una traducción romance de la Catena aurea en los reinos de Castilla y León, así como un nuevo testimonio de romanceamiento bíblico medieval.

\section{BIBLIOGRAFÍA}

Alvar, Carlos (2010): Traducciones y traductores. Materiales para una historia de la traducción en Castilla durante la Edad Media, Alcalá de Henares, Centro de Estudios Cervantinos.

Ansón Calvo, M. ${ }^{a}$ Carmen (1998): "Primicias de documentos sobre Asturias", en Scripta. Estudios en homenaje a Élida García, Oviedo, Universidad de Oviedo, pp. 11-28.

Avenoza Vera, Gemma (2008): "Las traducciones de la Biblia en castellano en la Edad Media y sus comentarios", en M. ${ }^{\text {a }}$ Isabel Toro Pascua (ed.): La Biblia en la literatura española, I. Edad Media, I/2. El texto: fuente y autoridad, Madrid, Trotta, pp. 13-75.

Avenoza Vera, Gemma (2009): "Manuscritos bíblicos ibéricos", en Eva B. Carro y Javier Durán (eds.): Códices Literarios Españoles. Interpretación, historia, técnicas y catalogación, Salamanca, Instituto de Historia del Libro y de la Lectura, pp. 55-70.

Avenoza Vera, Gemma (2010): "Traducciones, público y mecenazgo en Castilla (s. XV)", Romania, 128, 452-500.

Avenoza Vera, Gemma (2011): Biblias castellanas medievales, San Millán de la Cogolla, CiLengua.

Barrio, Florencio del (2016): "Cronología, registro y geografía de las variantes -mente, -miente y -mientre en el Corpus de Documentos Anteriores a 1700 (CODEA)", Scriptum digital, 5, pp. 85-102.

Benito Ruano, Eloy (1957): "El origen del Condado de Salinas", Hidalguía, 20, pp. 41-48.

Cano Aguilar, Rafael (1992): "Nuevas precisiones sobre como + subjuntivo", en Manuel Ariza, Rafael Cano, Josefa M. ${ }^{a}$ Mendoza y Antonio Narbona (eds.): Actas del II Congreso Internacional de Historia de la Lengua Española, Madrid, Pabellón de España, t. I, pp. 333-345.

Cátedra, Pedro M. (ed.) (1994): Enrique de Villena, Obras Completas I, Madrid, Biblioteca Castro Castro.

CODEA = Sánchez-Prieto Borja, Pedro (dir.): CODEA + 2015. Corpus de Documentos Españoles anteriores a 1800, <http://corpuscodea.es>.

CORHEN = Torrens Álvarez, María Jesús (dir.): Corpus Histórico del Español Norteño, $<$ corhen.es>.

Collijn, Isak y Erik Staaf (1908): Evangelios y epístolas con sus exposiciones en romance, según la versión castellana del siglo XV, hecha por Gonzalo García de Santa María del texto de Guillermus Parisiensis: Postilla super Epistolas et Evangelios, ahora de nuevo publicado conforme a la edición de Salamanca 1493, Uppsala, C. J. Lundström.

Company Company, Concepción (2009): "Artículo + posesivo + sustantivo y estructuras afines", en Concepción Company (dir.): Sintaxis histórica de la lengua española. Segunda parte: La frase nominal, vol. 1, pp. 759-880.

Company Company, Concepción (2014): "Adverbios en -mente", en Concepción Company Company (dir.), Sintaxis histórica de la lengua española. Tercera parte: Preposiciones, adverbios y conjunciones. Relaciones interoracionales, México D. F., UNAM/FCE, vol. 1, pp. 457-611. 
CORDE $=$ Real Academia Española, Corpus diacrónico del español, <corpus.rae.es/cordenet.html . DCECH = Corominas, Joan y José Antonio Pascual (1991-1997): Diccionario crítico etimológico castellano e hispánico, 6 vols., Madrid, Gredos.

DHLE = Real Academia Española (1933-36), Diccionario histórico de la lengua española, Madrid, Hernando, 2 vols.

Eberenz, Rolf (2000): El español en el otoño de la Edad Media. Sobre el artículo y los pronombres, Madrid, Gredos.

Enrique-Arias, Andrés (2008): “Apuntes para una caracterización de la morfosintaxis de los textos bíblicos medievales en castellano", en Johannes Kabatek (ed.), Sintaxis histórica del español y cambio lingüístico: Nuevas perspectivas desde las Tradiciones Discursivas, Frankfurt am Main/Madrid, Vervuert/Iberoamericana, pp. 109-125.

Enrique-Arias, Andrés (ed.) (2010): La Biblia Escorial I.I.6. Transcripción y estudios, Logroño, Fundación San Millán de la Cogolla/Cilengua.

Enrique-Arias, Andrés y F. Javier Pueyo Mena (2008-). Biblia Medieval, <http://www.bibliamedieval.es> [21/10/2014].

Esteve Barba, Francisco (1942): Biblioteca pública de Toledo. Catálogo de la colección de manuscritos Borbón-Lorenzana, Madrid, Impr. Góngora.

Fernández-Ordóñez, Inés (1994): "Isoglosas internas del castellano. El sistema referencial del pronombre átono de tercera persona", Revista de Filología Española, LXXIV, pp. 71-125.

Fernández-Ordóñez, Inés (2001): "Hacia una dialectología histórica. Reflexiones sobre la historia del leísmo, el laísmo y el loísmo", Boletín de la Real Academia Española, LXXXI, pp. 389-464.

Grespi, Giuseppina (2004): Traducciones castellanas de obras latinas e italianas contenidas en manuscritos del siglo XV en las bibliotecas de Madrid y El Escorial, Madrid, Biblioteca Nacional.

Guarienti, Angelici (ed.) (1953): S. Thomae Aquinatis, doctoris angelici. Catena aurea in quatuor evangelia. II. Expositio in Lucam et Ioannem, Roma, Marietti Editori.

Herrero Ruiz de Loizaga, F. Javier (2005): Sintaxis histórica de la oración compuesta en español, Madrid, Gredos.

Iñurreta Ambrosio, Esperanza (1989): Colección Diplomática del Archivo Municipal de Salvatierra (1256-1400), Donostia, Eusko Ikaskuntza.

Lacarra, José María y Ángel J. Martín Duque (1986): Colección diplomática de Irache. Volumen II (1223-1397. Índices 958-1397), Pamplona, Gobierno de Navarra.

Lapesa, Rafael (1981): Historia de la lengua española, Madrid, Gredos.

Lapesa, Rafael (2000): "Sobre el artículo ante posesivo en castellano antiguo", en Rafael Cano Aguilar y M. ${ }^{a}$ Teresa Echenique (eds.): Estudios de morfosintaxis histórica del español, Madrid, Gredos, pp. 413-435.

López de Haro, Alonso (1622): Nobiliario genealógico de los reyes y titvlos de España, Madrid, Luis Sanchez Impressor Real.

Matute Martínez, Cristina (2004): Los sistemas pronominales en español antiguo. Problemas y métodos para una reconstrucción histórica, Madrid, UAM, <http://www.lllf.uam.es/coser/publicaciones/cristina/1_es.pdf>.

Matute Martínez, Cristina (2013): "Hacia una caracterización dialectal de la interpolación en el castellano de la Edad Media”, en Emili Casanova Herrero y Cesáreo Calvo Rigual (eds.): Actas del XXVI Congreso Internacional de Lingüística y Filología Románica. Valencia 2010, Berlin, Walter de Gruyter, vol. 6, pp. 151-161.

Mohedano Hernández, José M. ${ }^{a}$ (1951): El Espéculo de los legos. Texto inédito del siglo XV, Madrid, CSIC.

Moral del Hoyo, María del Carmen (2015): "Hacia una dialectología gramatical del castellano medieval: cuestiones morfológicas del imperfecto y futuro de subjuntivo", Scriptum digital, 4, pp. 143-164. 
Morreale, Margherita (1958-59): "Los Evangelios y Epístolas de Gonzalo García de Santa María y las Biblias romanceadas en la Edad Media", Archivo de Filología Aragonesa, 10-11, pp. 277-289.

Muñío Valverde, José Luis (1995): "Pervivencia del participio de presente activo en español antiguo", Romanistisches Jahrbuch, 46, pp. 231-250.

Octavio de Toledo y Huerta, Álvaro S. (2016): Los relacionantes locativos en la historia del español, Berlin, De Gruyter Mouton.

Pons Rodríguez, Lola (2007): "La qual çibdat: las relativas con antecedente adjunto del siglo XIII a hoy. Evolución de un procedimiento cohesivo", Romanistisches Jahrbuch, 58, pp. 275-305.

Pons Rodríguez, Lola (2015): "La lengua del Cuatrocientos más allá de las Trescientas", en José M. ${ }^{a}$ García Martín (dir.): Actas del IX Congreso Internacional de Historia de la Lengua Española (Cádiz, 2012), Madrid/Frankfurt, Iberoamericana/Vervuert, pp. 393-430.

Pozuelo Rodríguez, F. Javier (1998): Documentación de la cuadrilla de Campezo: Arraia, Maeztu, Bernedo, Campezo, Lagran y Valle de Arana (1256-1515), Donostia, Eusko Ikaskuntza.

Pueyo Mena, F. Javier y Andrés Enrique-Arias (2013): "Los romanceamientos castellanos de la Biblia Hebrea compuestos en la Edad Media: manuscritos y traducciones", Sefarad, 73/1, pp. 165-224.

Revuelta, Josemaría (1982): Los jerónimos. Una orden religiosa nacida en Guadalajara, Guadalajara, Institución Provincial de Cultura "Marqués de Santillana".

Rodríguez Molina, Javier (2009): "Nota crítica a los versos 1934 y 225 del Poema de Mio Cid ¿un enigma paleográfico?", Zeitschrift für romanische Philologie, 125/1, pp. 85-105.

Rodríguez Molina, Javier (2010): La gramaticalización de los tiempos compuestos en español antiguo: cinco cambios diacrónicos, tesis doctoral, Madrid, UAM.

REW = Meyer-Lübke, Wilhelm (1935): Romanisches etymologisches Wörterbuch, Heidelberg, Carl Winters.

Ruiz García, Elisa (2002): Introducción a la codicología, Madrid, Fundación Germán Sánchez Ruipérez.

Sánchez, Nieves (dir.) (2000): Diccionario español de documentos alfonsíes, Madrid, Arco/Libros.

Sánchez González de Herrero, M. ${ }^{a}$ Nieves (dir.), Clara Grande López, Ana Lobo Puga, Vicente J. Marcet Rodríguez, Leyre Martín Aizpuru, Raquel Sánchez Romo (2014): Textos para la historia del español IX. Documentos de Miranda de Ebro, Alcalá de Henares, Universidad de Alcalá, Servicio de Publicaciones.

Torrell, Jean-Pierre (2002): Iniciación a Tomás de Aquino: su persona y su obra, Pamplona, EUNSA.

Torrens Álvarez, M. ${ }^{a}$ Jesús (2002): Edición y estudio lingüístico del Fuero de Alcalá (Fuero viejo), Alcalá de Henares, Fundación Colegio del Rey.

Ueda, Hiroto (en prensa): "Razones de la grafía doble $<\mathrm{ff}>$ en el castellano medieval. Analogías lingüísticas y paleográficas con <ss>”, Actas del XV Coloquio Internacional de Lingüística Iberorrománica CILIR2015 (Rouen, junio 2015).

Weber, Robert y Roger Gryson (2007): Biblia sacra iuxta vulgatam versionem, editio quinta, Stuttgart, Deutsche Bibelgesellschaft.

Fecha de recepción: 26 de enero de 2015

Fecha de aceptación: 12 de marzo de 2015 